\title{
¿GRAMATICALIZACIÓN O DESGRAMATICALIZACIÓN? REANÁLISIS Y SUBJETIVIZACIÓN DE VERBOS COMO MARCADORES DISCURSIVOS EN LA HISTORIA DEL ESPAÑOL*
}

\author{
CONCEPCIÓN COMPANY COMPANY
}

Universidad Nacional Autónoma de México

\section{INTRODUCCIÓN: EL PROBLEMA TEÓRICO}

La definición tradicional, y quizá más extendida hasta ahora, de gramaticalización ha puesto el énfasis, como se sabe, en la regularidad y unidireccionalidad del cambio: un proceso mediante el cual una forma léxica o construcción, en contextos pragmáticos y morfosintácticos específicos, asume una función gramatical, o bien una entidad o construcción ya gramatical adquiere una función aún más gramatical ${ }^{1}$. Una definición tambiên estándar, complementaria de

\footnotetext{
- Una version preliminar abreviada de este trabajo fue leída en el 7th Hispanic Linguistics Symposium, llevado a cabo en Albuquerque, University of New Mexico, los dias 1417 de octubre de 2003. Un agradecimiento muy especial a Rena Torres Cacoullos tanto por la lectura y comentarios críticos de un par de versiones preliminares de este trabajo, por algunas referencias bibliográficas que me permitieron matizar y enriquecer la argumentación, así como por su generosidad en el diálogo. A Elizabeth Traugott muchas gracias por el reto de sus preguntas téricas, surgidas de la lectura de un par de versiones preliminares. A Rosa Maria Ortiz Ciscomani gracias también por una lectura crítica de un primer manuscrito de este trabajo. A Joan Bybee y Joaquín Garrido, gracias por la iluminadora plática de sobremesa. A Álvaro Octavio de Toledo y a Salvador Pons Borderfa les debo el rigor de su lectura crítica que, indudablemente, ayudo a matizar y enriquecer varios puntos. A Rosa Maria Espinosa Elorza le debo algunos ejemplos y su constante disponibilidad para la lectura generosa. Los desatinos y errores de análisis son, como se dice en estos casos, total responsabilidad mifa.

' Cf., entre muchos otros, Bemd Heine, "Grammaticalization», en The handbook of historical linguistics, B. D. Joseph y R. Janda (eds.), Malden-Oxford, Blackwe1l, 2003, págs. 575-601; Bernd Heine y Mechthild Reh, Grammaticalization and reanalysis in African languages, Hamburg, Helmut Buske, 1984, especialmente págs. 20-22; Bernd Heine, Ulrike Claudi y Fredericke Hünnemeyer, Grammaticalization. A conceptual framework, Chicago, The University of Chicago
}

RFE, LXXXIV, 2004, 1. , págs. 29-66 
la anterior, es que la gramaticalización consiste en la fijación de estrategias discursivas, de manera que los fenómenos lingüísticos que, en un estado de lengua dado, operan en un nivel discursivo o textual, en un nivel más pragmático, se convierten con el paso del tiempo en construcciones gramaticales convencionales, carentes ya de condicionamientos pragmáticos ${ }^{2}$.

Ambas definiciones presuponen automáticamente que las formas linguísticas son preexistentes y que, por tanto, en el cambio gramatical no hay creación ex novo, sino que se trata en esencia de revolver, recrear, la materia léxica, discursiva o gramatical previas. Tampoco, bajo esta perspectiva, habría pérdida absoluta, ya que en la sintaxis siempre habrá modo de expresar un contenido dado. Retomaremos esta idea más adelante, cuando sopesemos el problema téorico.

Me interesa particularmente subrayar un aspecto teórico subyacente a las dos definiciones anteriores, a saber, que el proceso de cambio es unidireccional, esto es, la dirección o camino diacrónico usual de la gramaticalización es siempre de formas libres $>$ formas ligadas, de uso optativo > uso obligatorio, de discurso-pragmática $>$ sintaxis, de sintaxis $>$ morfología, y no viceversa, pudiendo, desde luego, las formas permanecer por siglos en estados intermedios del proceso evolutivo, $y$ pudiendo, desde luego, formas innovadoras y formas conservadoras —derecha e izquierda del canal evolutivo, respectivamentecoexistir por siglos, incluso bajo un mismo exponente formal. La gramaticalización tradicional, por tanto, puede ser caracterizada como un descenso de nivel de lengua, en cuanto que inicia en el léxico o el discurso y concluye en la sintaxis o la morfología.

En (1) se ejemplifica un par de caminos o canales unidireccionales bien conocidos en la literatura sobre gramaticalización ${ }^{3}$; el canal en sí mismo consti-

Press, 1991, pág. 226; Paul Hopper y Elizabeth C. Traugott, Grammaticalization, Cambridge, Cambridge University Press, 1993, cap. 3; y los clásicos Jerzy Kurylowicz, «The evolution of grammatical categories», Diogenes, 55, 1965, págs. 55-71, pág. 69, y Antoine Meillet, «L'evolution des formes grammaticales», en Linguistique historique et linguistique générale, vol. 1, Paris, Edouard Champion, 1965 [1912], págs. 130-149.

${ }^{2}$ Cf., por ejemplo, Elizabeth C. Traugott, «On the rise of episternic meanings in English: An example of subjectification in semantic change», Language, 65:1, 1989, págs. 31-55 y «Constructions in grammaticalization", en The handbook of historical linguistics, B. D. Joseph y R. Janda (eds.), Malden-Oxford, Blackwell, 2003, págs. 624-647; José Luis Girón Alconchel, «Procesos de gramaticalización del espaffol clásico al moderno», en Actas del V Congreso Internacional de Historia de la Lengua Española, M. T. Echenique et al. (eds.), Madrid, Gredos, 2002, págs. 103-121; Concepcion Company Company, «La gramaticalización en la historia del español», en Gramaticalización y cambio sintáctico en la historia del español, número monográfico de Medievalia, 35, 2003, págs. 1-63.

${ }^{3}$ Cf, para el primer canal, Talmy Givón, On understanding grammar, New York, Academic Press, 1979, las págs. 209-210, y para el segundo, Hopper y Traugott, Grammaticalization, 1993, pág. 7. Pongo entre paréntesis la última etapa en ambos canales, ya que, en mi opinión, no es obligatoria la pérdida. 
tuye un continuum evolutivo y la progresión en él es gradual. En (2) se muestra un ejemplo ortodoxo, bien conocido, de esta direccionalidad del proceso en la diacronía del español: la gramaticalización de un adverbio locativo en un afijo ${ }^{4}$. En (2a), siglo XIII, la forma $y<$ latín $i b i$, funciona como una palabra plena, adverbio locativo, y como tal tiene movilidad posicional, tiene anclaje referencial anafórico (muy claro en el segundo ejemplo de $2 a$ ) y entra en construcción con distintos tiempos de haber, en (2b), siglo XVI, es ya un afijo integrado a una base verbal de carácter único: sólo en presente de indicativo, la forma, por tanto, se ha degradado, se ha descategorizado, pasando de sintaxis > morfología y de forma libre > forma ligada, y ha opacado totalmente su valor locativo, de ahí que pueda aparecer en la oración otro adverbio locativo, allá, de significado próximo al etimológico $y$, como en (2c).

(1) discurso $>$ sintaxis $>$ morfología $>$ morfofonémica ( $>$ pérdida) palabra léxica plena > palabra gramatical $>$ clítico $>$ afijo flexivo $(>\varnothing)$

(2) a. Otras yslas y a menores, que son de la pertenencia de Europa (Crónica general, 5.7b)

E este pozo era bazio e no y aula agua (Fazienda de ultramar, 51)

E por esto era muy mal quisto de todas las gentes, mas no osauan yr contra el por que non auie y qui los defender (Crónica general, 9.30b)

b. El mesmo desasosiego ay entre los naturales (Documentos lingüísticos de la Nueva España, 1532, 13.99)

c. porque alla ay mucha abundancia y aca falta (Léxico histórico del español de Mexico, 1525, s.v. haber)

Como consecuencia del auge de la investigación en sintaxis a la luz del marco térico —o mejor, marcos téoricos- de la gramaticalización, en los últimos diez años, y con gran insistencia en los últimos cuatro o cinco años, se ha venido estudiando también un número no desdeñable de cambios que muestra una direccionalidad evolutiva inversa a la postulada por la gramaticalización, a saber, de formas con estatus gramatical sintáctico > formas con estatus menos gramatical, de formas ligadas $>$ formas libres, es decir, de palabra gramatical > palabra léxica, o de morfología > sintaxis, por ejemplo, afijo > clítico, o bien de sintaxis > discurso. Es posible caracterizar este segundo cambio como un ascenso de nivel de lengua, en cuanto que se inicia en la sintaxis o la morfología y pasa a un nivel superior ${ }^{5}$.

${ }^{4}$ Cf. Érica García, «Morphologization; a case of reversible markedness?, Probus, 3:1, 1991, págs. 23-54, y Axel Hernández Díaz, Construcciones existenciales con el verbo haber en el español. Estructura y evolución, tesis de maestría inédita, México, Universidad Nacional Autónoma de México, 2003; los ejemplos de (2) están tomados de Herrández Díaz, con excepción de (2c) que proviene de Concepción Company y Chantal Melis, Lexico historico del español de México. Régimen, clases funcionales, variación gráfica y frecuencias, México, Universidad Nacional Autónoma de México, 2002.

${ }^{5}$ Cf. a este respecto, los términos upgrading y downgrading de Frederick Newmeyer, en «Deconstructing grammaticalization», Language Science, 23, 2001, págs. 187-229. 
En (3) se ejemplifica un par de casos con esta direccionalidad. Se trata, como vemos, de un proceso inverso al de la gramaticalización, y en este proceso inverso las formas prescinden o se liberan de sus antiguas restricciones semánticas y distribucionales y pasan a operar en un nivel superior de lengua; por supuesto, adquieren restricciones semánticas y distribucionales de otra naturaleza. Este tipo de cambios suele ser englobado bajo una diversidad de etiquetas conceptuales, que se recubren en ciertos aspectos al mismo tiempo que suponen matices distintos del proceso de cambio: lexicalización, desgramaticalización, adaptación, refuncionalización, pragmatización, etc. ${ }^{6}$. Una de ellas, desgramaticalización, será la empleada en este trabajo, como un término operativo que, por el momento, sirva para identificar cambios con díreccionalidad inversa a la gramaticalización tradicional, definida al inicio de este trabajo.

(3) a. sufijo de 1 ". persona plural sujeto - mid / -muid $>$ pronombre independiente muid (irlandés) ${ }^{7}$

b. verbo bitransitivo pleno: dale a mis obras el debido premio (siglo Xv) ${ }^{8}>$ marcador pragmático intensivo: jdale que dale, siempre con lo mismo!

Los fenómenos de desgramaticalización suelen causar amplia polémica porque tienen un comportamiento huidizo para ser etiquetados fácilmente en una tipología de cambios sintáctico-semánticos. Hay varias posturas al respecto, al menos cuatro, no siempre complementarias, que van desde ignorar su existencia hasta considerarlos una gramaticalización tradicional. Las posiciones teóricas son: a) ignorar o minimizar su existencia o efectos en la diacronía de las lenguas, tal es la posición de Lehmann, en su libro, ya clásico, de $1982^{9}$; b) aceptar que es un cambio posible y que la diacronía de la lengua se puede mover en ambas direcciones, gramaticalización y desgramaticalización, si bien reconocen que la primera es mucho más frecuente que la segunda, tal es la posición de Haspelmath, Heine o Lass ${ }^{10}$; c) un número importante de estudiosos

6 Para una revisión de los términos, véanse Bernd Heine, «On degrammaticalization», en Historical Linguistics 2001, B. J. Blake y K. Burridge (eds.), Amsterdam-Philadelphia, John Benjamins, 2003, págs. 163-180.

7 Tomado de Joan $\mathbf{L}$. Bybee, Revere Perkins y William Pagliuca, The evolution of grammar. Tense, aspect, and modality in the languages of the world, Chicago, The University of Chicago Press, 1994, págs. 13-14.

8 Tomado de Concepción Company, «Multiple dative-marking grammaticalization. Spanish as a special kind of primary object language», Studies in Language, 25:1, págs. 1-47, pág. 29.

${ }^{2}$ Cf. Christian Lehmann, Thoughts on grammaticalization, Munchen-Newcastle, Lincom Europa, 1995 [1982], especialmente, págs. 19-20.

${ }^{10}$ Cf. Martin Haspelmath, "Why is grammaticalization irreversible?", Linguistics, 37:6, 1999, págs. 1043-1068; Heine, «On degrammaticalization», citado en la nota 7, y Roger Lass, «Rernarks on (uni)directionality", en Pathways of change. Grammaticalization in English, O. Fisher, A. Rosenbach y D. Stein (eds.), Amsterdam-Philadelphia, John Benjamins, 2000, 
defiende que los cambios que muestran esa direccionalidad inversa son en esencia gramaticalizaciones, si bien peculiares, en cuanto a que escapan o se sustraen a algunas de las características de los procesos de gramaticalización, como Brinton, Company, Traugott o Travis ${ }^{11}$; y finalmente $d$ ) en una postura complementaria de la anterior, se sostiene que la desgramaticalización no es un proceso específico distinto de la gramaticalización, sino que difiere de aquella en cuanto que pone el énfasis en el resultado del proceso de cambio, tal es el planteamiento de Norde ${ }^{12}$.

Un tipo de cambio sintáctico-semántico especialmente conflictivo ya que participa tanto de la direccionalidad de la gramaticalización como de la direccionalidad de la desgramaticalización es el conocido como subjetivización. En la mayoría de estudios sobre el tema (véase infra, referencias en $\S 2$ ), se observa que cuando las formas se recargan pragmáticamente y adquieren significados valorativos - subjetivos o intersubjetivos - experimentan tanto descategorización y debilitamiento del significado referencial etimológico, que son cambios típicos de la gramaticalización, cuanto adquieren una mayor autonomía e independencia de la estructura sintáctica, que son cambios típicos de la desgramaticalización. En este sentido, me atrevo a calificar la subjetivización como un cambio bastante paradójico, además de conflictivo. En ella precisamente nos centraremos en este trabajo, en concreto, en la subjetivización de verbos en marcadores discursivos.

Un cambio íntimamente relacionado con la subjetivización es la creación de marcadores discursivos o pragmáticos en las lenguas, y ellos constituyen un caso particularmente transparente del conflicto y la paradoja. En efecto, la mayoría de los marcadores, como se sabe, se crea a partir de las categorías léxicas y gramaticales existentes en la lengua en cuestión, vía la descategorización y debilitamiento semántico de dichas categorías, y la mayoría de ellos surge también como resultado de procesos de subjetivización, vía un reforzamiento in-

págs. 207-227. Según Haspelmath, más del $90 \%$ de cambios en las lenguas son gramaticalizaciones, mientras que es muy reducido el número de cambios identificables como degramaticalizaciones.

$"$ Cf. Laured J. Brinton, Pragmatic markers in English. Grammaticalization and discourse functions, Berlin-New York, Mouton de Gruyter, 1996; Concepción Company, «Gramaticalización por subjetivización como prescindibilidad de la sintaxis», Nueva Revista de Filologia Hispánica, en prensa, y «Subjectification of verbs into discourse markers. Semantic-pragmatic change only?», en Pragmaticalization and modalization, N. Delbecque y B. Comillie (eds.), Amsterdam, John Benjamins; Elizabeth C. Traugott, «The role of the development of discourse markers in a theory of grammaticalization», ponencia leída en el 12 th International Conference on Historical Linguistics, Universidad de Manchester, 1995; Catherine E. Travis, «Pragmatic extensions in grammar and discourse: The development of discourse markers», comunicación leída en Santa Fe Workshop on the Grammar/Pragmatic Interface, 2003.

12 Muriel Norde, «Degrammaticalization: Process or result?», comunicación leída en el I6th International Conference on Historical Linguistics, Universidad de Copenhagen, 2003. 
ferencial pragmático. Este carácter de categoría derivada o secundaria los convierte en una zona gramatical valiosa para probar las relaciones y límites entre gramática y pragmática o entre sintaxis y semántica, y, de manera general, para comprobar la dinámica mediante la cual una categoría léxica se subjetiviza, y para comprobar el conflicto entre gramaticalización y desgramaticalización; es decir, los marcadores discursivos son zona de prueba teórica y empírica ${ }^{13}$. Ellos son justamente el objeto de estudio de este trabajo.

El objetivo de este estudio es doble, uno de naturaleza teórica, otro de naturaleza descriptiva, ambos complementarios. Por una parte, intentaré mostrar por qué la subjetivización tiene, por lo regular, como resultado un situación que podría ser definida como desgramaticalización, en la medida en que arroja casi siempre formas más independientes y autónomas, esto es, intentaré hacer explícita la causa de la paradoja arriba mencionada, mostrando la relación constante entre subjetivización y autonomía sintáctica, vía la prescindibilidad de la sintaxis. Por otra parte, analizaré la gran flexibilidad categorial que muestra el verbo en español para descategorizarse y recategorizarse en marcadores pragmáticos discursivos ${ }^{14}$, vía procesos de subjetivización, centrándome para ello en cambios como el ejemplificado en (3b). Esta flexibilidad es un fenómeno teórica y diacrónicamente interesante que, sin embargo, suele ser pasado por alto en los trabajos sobre la historia de nuestra lengua.

Conjuntando ambos objetivos, intentaré sopesar si el cambio recurrente de la historia del español verbo > marcador discursivo pragmático es una gramaticalización o una desgramaticalización o, mejor aún, en qué medida participa de uno y otro tipo de cambio, para proponer, o al menos reflexionar sobre cuál es la definición de gramática y gramaticalización idóneas para integrar este tipo de fenómenos diacrónicos en los marcos teóricos actuales de gramaticalización.

Los datos para el ańlisis están basados en los dos corpus electrónicos de la Real Academia Española (www.rae.es): Corpus Diacrónico del Español (CORDE) y Corpus del Español Actual (CREA), en el corpus electrónico Corpus del Español (CE) de Mark Davies (www.corpusdelespañol.org), así como en el

${ }^{13}$ Con frecuencia, las zonas de prueba clásicas de la gramática tradicional corresponden también a categorías secundarias o derivadas, tal es el caso, por ejemplo, de la clitización y la pasivización para comprobar el estatus de objeto directo de un nominal.

14 Para los fines de este trabajo, emplearé el término 'marcador pragmático discursivo' como una etiqueta de cobertura para todas las formas que a partir de verbos plenos adquieren valores pragmáticos y funciones discursivas. Remito a Lawrence Schourup, "Discourse markers", Lingua, 107, 1999, págs. 227-265, para la amplia gana de términos con que suele ser denominado este tipo de formas, y las implicaciones teónicas subyacentes a los diferentes nombres. Véase también los dos trabajos de Bruce Fraser, «Pragmatic markers», Pragmatics, 6:2, 1996, págs. 167-190, y «What are discourse markers?», Joumal of Pragmatics, 31, 1999, págs. 931-952. 
diccionario de construcción y régimen Léxico histórico del español de México (LHEM) de Company y Melis (referido en la nota 5), además de ejemplos de habla espontánea de español de México y español peninsular recogidos en los últimos dos años. Ocasionalmente se incorporan datos de otras modalidades hispanohablantes, concretamente del español argentino.

El trabajo, además de la presente Introducción, está estructurado en cuatro apartados. En primer lugar, apartado 2, definiré el cambio base del análisis, subjetivización, señalaré sus características sintácticas y semánticas, e intentaré mostrar por qué, en líneas generales, una subjetivización supone un proceso de prescindibilidad sintáctica, alcanzando, incluso, la forma o expresión subjetivizada autonomía sintáctica, vía debilitamiento y pérdida de sintaxis. En 3, el apartado más extenso, expondré algunos de los verbos que en español experimentan el cambio verbo > marcador discursivo pragmático, y señalaré las características sintácticas y semánticas comunes a todos ellos. El apartado 4 constituye un análisis más detaliado del cambio en dos de esos verbos, con el fin de mostrar los contextos que propician su descategorización como verbos y su recategorización como marcadores; haré hincapié en este último apartado en el hecho de que en todos los casos el nuevo significado discursivo-pragmático está conceptual y estructuralmente relacionado con el significado conservador referencial etimológico del verbo base. En 5 sopesaré el problema té́rico planteado al inicio del artículo, examinando cuáles de las características diacrónicas de estos cambios son propias de una gramaticalización y cuáles lo son de una desgramaticalización. Cierran unas conclusiones.

\section{SUBJETIVZACIÓN: CANCELACIÓN SINTÁCTICA + ENRIQUECIMIENTO PRAG- MÁTICO}

La definición tradicional de subjetivización es que se trata de un proceso dinámico mediante el cual las valoraciones del hablante ante lo comunicado o ante el evento en general encuentran codificación explícita en la gramática de una lengua, llegando a constituir un significado altamente simbólico y convencional en esa lengua. Pueden encontrar codificación explícita tanto significados pragmáticos subjetivos, esto es, la perspectiva, actitud y punto de vista del hablante respecto a las entidades objeto de la comunicación y respecto del evento, cuanto significados pragmáticos intersubjetivos, esto es, su interacción y proximidad o distancia, afectiva o social, respecto del oyente ${ }^{15}$. Se acepta

is Cf., entre otros, Ronald W. Langacker, «Observations and speculations on subjectivity», en Iconicity in syntax, J. Haiman (ed.), Amsterdann-Philadelphia, John Benjamins, 1985, pags. 109-150, «Subjectification», en Concept, image and symbol. The cognitive basis of grammar, Berlin-New York, Mouton de Gruyter, 1991, págs. 315-342, «Losing control; Grammatici- 
tambiên generalmente que el 'yo-aquí-ahora' es el ángulo usual de perspectiva del hablante en el uso lingiístico ${ }^{16}$, de manera que el eje que parece estructurar la lengua es no subjetivo-subjetivo, o débilmente subjetivo-fuertemente subjetivo, en lugar de objetivo-subjetivo.

Los ejemplos de (4) y (5) muestran un contraste entre un enunciado no subjetivo (serie a) y un enunciado subjetivo valorativo (serie b). En (4a) y (5a) los verbos de movimiento, venir e ir, mantienen su significado pleno de desplazamiento desde o hacia una meta locativa, en (4b) y (5b) los verbos han perdido su significado etimológico de desplazamiento, y funcionan como marcadores pragmáticos mediante los cuales el hablante evalúa, confirma o expresa su punto de vista respecto de lo dicho por su interlocutor.

(4) a. Venga o no venga, pienso salir a pasear

b. - ¿Quieres un té o un café? - Venga, un café (Salazar 2003)

(5) a. Todos los sábados Juana va al mercado a comprar flores

b. - Supongo que ganaron los demócratas -Qué va, menuda falta de madurez política corre en estos tiempos

zation, subjectification and transparency", en Historical semantics and cognition, A. Blank y P. Koch (eds.), Berlin-New York, Mouton de Gruyter, 1999, pags. 147-175; Jan Nuyts, «Subjectivity as an evidential dimension in epistemic modal expressions», Joumal of Pragmatics, 33, 2001, págs. 383-400; y muy especialmente los trabajos de Elizabeth $\mathrm{C}$. Traugoth, «Subjectification in grammaticalization», en Subjectivity and subjectivisation. Linguistic perspectives, D. Stein y S. Wright (eds.), Cambridge, Cambridge University Press, 1995, pags. 31-54, «The rethoric of counter-expectation in semantic change: A study in subjectifications, en Historical semantics and cognition, A. Blank y P. Koch (eds.), Berlin-New York, Mouton de Gruyter, 1999, pags. 177196, «The role of pragmatics in semantic change», en Pragmatics in 1998. Selected Papers from the 6th International Pragmatics Conference, J. Verschueren (ed.), Antwerp, International Pragmatics Association, 1999, págs. 93-102, «Constructions in grammaticalization», en The handbook of historical linguistics, B. D. Joseph y R. Janda (eds.), Malden-Oxford, Blackwell, 2003, págs. 624-647, y de Traugott y Richard B. Dasher, Regularity in semantic change, Cambridge, Cambridge University Press, 2002; también Arie Verhagen, «Subjectification, syntax and communication", en Subjectivity and subjectivisation. Linguistic perspectives, D. Stein y S. Wright (eds.), Cambridge, Cambridge University Press, 1995, pasgs. 103-128, «'The girl that promised to become something': An exploration into djachronic subjectification in Dutchs, en The Berkeley Conference on Dutch Linguistics 1997: The Dutch Language at the Millenium, Th. F. Shannon y J.P. Snapper (eds.), Lanham, MD, University Press of America, 2000, pags. 197-208. Las definiciones en estos autores se recubren en buena parte con la definición y concepto de 'modalidad' de la tradición europea, entendida como «la actitud con que el hablante se enfrenta al enunciado»; cf. Salvador Pons Bordería, «Los apelativos oye y mira o los límites de la conexión», en Marcadores del discurso. Teorfa y análisis, M. A. Martín Zorraquino y E. Montolío (eds.), Madrid, Arco Libros, 1998, págs. 213-228, especialmente la pág. 220. Empleo los términos subjetivización y subjetividad, por ser más comunes en los estudios sobre gramaticalización.

${ }^{16}$ Cf. Émile Benveniste, «De la subjetividad en el lenguaje», en Problemas de lingǘstica general, México, Siglo XxI, 1971 [1958], págs. 179-187, especialmente la pág. 182, y John Lyons, «Deixis and subjectivity: Loquor ergo sum», en Speech, place and action, R. J. Jarvella y W. Klein (eds.), Chichester, John Wiley and Sons, 1982, págs. 101-124, especialmente la pág. 107. 
En la bibliografía especializada sobre subjetivización y sobre marcadores discursivos pragmáticos se identifican varios cambios, semánticos y sintácticos, estrechamente relacionados, que son consecuencia y/o condición para que se produzca un proceso de subjetivización como el ejemplificado en (4b) y en (5b), a saber: debilitamiento o pérdida de significado referencial, proceso inferencial metafórico-metonímico, debilitamiento o pérdida del control agentivo del sujeto, ampliación del alcance predicativo, fijación y automomía de la predicación, reducción o pérdida de capacidades sintácticas. Examinemos uno por uno.

I) Debilitamiento y/o vaciamiento del significado referencial etimológico originario.-La mayorfa de los autores considera que este debilitamiento referencial es prerrequisito para que las formas adquieran una función subjetiva 0 intersubjetiva ${ }^{17}$.

En este punto hay una cierta polémica, en la bibliografía sobre marcadores discursivos respecto a si las formas subjetivizadas arrastran, debilitado, el significado etimológico, manteniendo formas referenciales y subjetivas un significado común de alguna naturaleza, o si la expresión subjetiva se desvincula totalmente del significado etimológico referencial, creándose una situación de (cuasi) homonimia entre forma conservadora y forma innovadora ${ }^{18}$.

${ }^{17}$ Cf., entre ouros, Joan L. Bybee y William Pagliuca, «Cross-linguistic comparison and the development of grammatical meaning», en Historical semantics and historical word-formation, J. Fisiak (ed.), Berlin, Mouton de Gruyter, 1985, págs. 59-83, en concreto la pág. 74; Bybee, Perkins y William Pagliuca. The evolution of grammar. Tense, aspect, and modality in the languages of the world, citado anteriomente, las pags. 6 y 19; Lyle Campbell, «What's wrong with grammaticalization?», Language Sciences, 23, 2001, págs. 113-161, especialmente 118-121, Concepción Company, «Gramaticalización, debilitamiento semántico y reanálisis. El posesivo como artículo en la evolución sintáctica del español», Revista de Filología Espantola, 81:1-2, 2001, pags. 49-87; Elizabeth C. Traugott, «From propositional to textual and expressive meanings. Some semantic-pragmatic aspects of grammaticalization», en Perspectives on historical linguistics, W. P. Lehmann y Y. Malkiel (eds.), Amsterdam, John Benjamins, 1982, págs. 245-272, especialmente la pág. 258, «Subjectification in grammaticalization», en Subjectivity and subjectivisation. Linguistic perspectives, D. Stein y S. Wright (eds.), Cambridge, Cambridge University Press, 1995, págs. 31-54, especialmente pág. 39; Traugott y Dasher, Regularity in semantic change, citado en la nota 16, págs. 31 y 149 .

${ }^{18}$ Para la primera postura, cf. Concepcion Company, «Subjectification of verbs into discourse markers. Semantic-pragmatic change only?», citado en la nota 12; Scott A. Schwenter, «Some reflections on o sea: A discourse marker in Spanish", Joumal of Pragmatics, 25, 1996, págs. 855874; Catherine B. Travis, «The natural semantic metalanguage approach to discourse markers», en Approaches to discourse particles, K. Fischer (ed.), Annsterdam-Philadelphia, John Benjamins, en prensa. Para la segunda posición, que defiende un resultado de homonimia, cf. los dos trabajos de Fraser «Pragmatic markers» $y$ "What are discourse markers?», citados en la nota 14. Para un estado de la cuestión al respecto, puede consultarse el trabajo de Schourup, «Discourse markers» de 1999, citado en la nota 14. Por mi parte considero que el hecho de que regularmente el cambio sintáctico-semántico sea acumulativo, de manera que el valor innovador convive por siglos con el valor conservador etimológico de una forma, sugiere que los dos, o más, valores establecen una relación de tipo red semántica más que desvincularse y crear una situación de homonimia. 
II) Cambios metafóricos-metonímicos de naturaleza inferencial discursiva-pragmática.--La subjetivización se produce siempre, como es sabido, a través de una manipulación pragmática de las formas, de tipo inferencial e implicacional, que realiza el hablante-oyente individual en contextos y usos discursivos específicos. El hablante carga el mensaje, de manera velada, con alguna apreciación o valoración personal, que invita al oyente a interpretar más de lo que realmente se dice; el oyente infiere correctamente la perspectiva o punto de vista que el hablante quería transmitir y supone que el matiz subjetivo inferido es un valor establecido de la forma o construcción emitida por el hablante; esta inferencia individual pasa, con el transcurso del tiempo, a ser una inferencia convencional compartida por los hablantes de la comunidad lingüística, de manera que el nuevo valor inferido llega a volverse un significado estándar, un significado convencional cristalizado en gramática, acumulado la mayoría de las veces al valor conservador etimológico ${ }^{19}$. En resumen, el cambio sintáctico-semántico se desliza siempre con la siguiente direccionalidad: inferencia conversacional-discursiva individual $\rightarrow$ inferencia conversacional-discursiva compartida $\rightarrow$ inferencia convencional generalizada.

III) Debilitamiento o pérdida del control agentivo del sujeto.-Típicamente en las expresiones subjetivas se atenúa, debilita e incluso se pierde el control agentivo del sujeto sobre la acción significada en el enunciado, debilitamiento que se manifiesta fundamentalmente en el hecho de que los sujetos sintácticos de las expresiones subjetivas suelen ser entidades inanimadas, no agentivas, que son, por tanto, no volitivas e incapaces de llevar a cabo conscientemente la acción del verbo ${ }^{20}$. Así, por ejemplo, el enunciado se te va a caer el café tiene un sujeto inanimado, el café, sin control agentivo, la expresión no indica movi-

19 Cf., entre muchos otros, Gabriele Diewald, «A model for relevant types of contexts in grammaticalization», New reflections on grammaticalization, I. Wischer y D. Diewald (eds.), Amsterdann, John Benjamins, 2002, págs. 103-120; Chantal Melis, «Verbos de movimiento. La formación de los futuros perifrásticos», en Sintaxis histórica de la lengua española, primera parte: La frase verbal, C. Company (dir.), México, Fondo de Culnura Económica y Universidad Nacional Autónoma de México, en prensa; José Pinto de Lima, «Grammaticalization, subjectification and the origin of phatic markers», en New reflections on grammaticalization, I. Wischer y G. Diewald (eds.), Amsterdan-Philadelphia, John Benjarnins, págs. 363-378; Scott A. Schwenter y Elizabeth C. Traugott, «Invoking scalarity: The development of in fact», Joumal of Historical Pragmatics, 1:1, 2000, págs. 7-25, y el capítulo 2 del libro de Traugott y Dasher, Regularity in semantic change, de 2002 , citado en la nota 15 y 17.

${ }^{20}$ Cf. Bybee y Pagliuca, "Cross-linguistic comparison and the development of grammatical meaning», citado en la nota 18, especialmente las págs. 65, 67; Langacker, «Subjectification», citado en la nota 15, especialmente la pág. 342, eLosing control: Grammaticization, subjectification and transparency", citado en la nota 15, "Subjectification and grammaticization», en Grammar and conceptualization, Berlin-New York, Mouton de Gruyter, 2000, págs. 297-315, especialmente las págs. 301, 305, Traugott, «Subjectification in grammaticalization», citado en la nota 15, especialmente las págs. 34-35, y Traugott y Dasher, Regularity in semantic change, pág. 21. 
miento alguno, sino que es un enunciado subjetivo con el que el hablante previene al oyente de los efectos negativos del evento.

Este debilitamiento del sujeto tiene, a su vez, como consecuencia una atenuación o debilitamiento de la estructura argumental de la oración y por tanto de las relaciones que contraen los constituyentes que integran el enunciado subjetivo, de tal manera que la oración subjetiva toda admite sólo una interpretación global, y no vía el significado de sus constituyentes individuales ${ }^{21}$, significado global con el cual el hablante manifiesta su propio punto de vista sobre el evento.

Iv) Ampliación del alcance de la predicación. Las formas subjetivizadas se sitúan por lo regular lo más a la izquierda posible del enunciado -o también en español completamente a la derecha-, al punto de que suelen iniciarlo - o concluirlo-, de manera que su significado incide sobre la expresión oracional toda, de manera global, y no sobre alguno de los constituyentes o alguno de los tramos sintácticos de ese enunciado, es decir, la subjetivización produce ampliación del alcance estructural de la predicación, llegando muchas veces a un alcance extraoracional discursivo ${ }^{22}$. Este cambio, como veremos, constituye un serio contraejemplo a la direccionalidad menos gramatical > más gramatical postulada por la gramaticalización.

v) Fijación y autonomía de la predicación. La subjetivización puede evolucionar en una expresión fija. En el caso de la creación de marcadores discursivos - muchos de ellos resultado de subjetivización-, además de formar éstos expresiones fijas, constituyen por lo regular una predicación autónoma en sí mismos, prosódicamente independientes, separados del contexto circundante por pausas o quiebres entonativos, o suelen en general exhibir una mala integración sintáctica, ya que se aíslan del resto de los constituyentes de la oración en la que aparecen ${ }^{23}$. Este cambio se relaciona estrechamente con el que sigue.

2] Cf. Ans van Kemenade, «Functional categories, morphosyntactic change, grammaticalization», Linguistics, 37:6, págs. 997-1010, especialmente pág. 1007; Traugott y Dasher, Regularity in semantic change, ya citado en notas anteriores, especialmente las págs. 22-23; Verhagen, «Subjectification, syntax and communication», citado en la nota 15, en particular la pág. 113.

22 Cf. Sylvia Adamson, «A lovely little example. Word order options and category shift in the premodifying string”, en Pathways of change. Grammaticalization in English, $\mathrm{O}$. Fischer, A. Rosenbach y D. Stein (eds.), Amsterdam-Philadelphia, John Benjamins, págs. 39-66, especialmente pág. 40; Lyle Campbell, «What's wrong with grammaticalization?», Language Sciences, 23, 2001, págs. 113-161, especialmente 137; Whitney Tabor y Elizabeth Traugott, «Structural scope expansion and grammaticalization», en The limits of grammaticalization, A. G. Ramat y P. J. Hopper (eds.), Amsterdan-Philadelphia, John Benjamins, 1998, págs. 229-272; Traugott, «Subjectification in grammaticalization», citado en las notas 16 y 18; Ilse Wischer, "Grammaticalization vs. lexicalization. Methinks there is some confusion», en Pathways of change. Grammaticalization in English, O. Fisher, A. Rosenbach y D. Stein (eds.), Amsterdam-Philadelphia, John Benjamins, págs. 355-370, en particular la pág. 357.

${ }^{23}$ Cf. Ángel Alonso-Cortés, «Las construcciones exclamativas. La interjección y las expresiones vocativas", en Gramática descriptiva de la lengua española, I. Bosque y V. Demonte 
v1) Pérdida de capacidades sintácticas. La subjetivización puede dar lugar a una reducción o pérdida de las propiedades sintácticas usuales de la forma o construcción que experimenta el proceso. En general, las expresiones subjetivas muestran una sintaxis empobrecida, incapaces de ser parafraseadas, e imposibilitadas de exhibir una distribución normal, plena, esto es, no pueden tomar la modificación y complementación normal que tomaría la forma en cuestión en su empleo no-subjetivo, llegando muchas veces a cero sintaxis ${ }^{24}$. Así, en los enunciados anteriores de (4b) y (5b), no se les puede añadir nada a las formas venga o va, ni tampoco se puede decir, por ejemplo, *se te va a caer el café colombiano, manteniendo el valor subjetivo.

De los seis cambios involucrados en una subjetivización, cinco son procesos de debilitamiento, desgaste y pérdida, semántica y/o sintáctica, mientras que sólo uno, el cambio II), constituye un proceso de enriquecimiento pragmático. El conjunto de los cambios crea un conflicto para caracterizar la subjetivización, en cuanto que los cambios I) II) y III) son los mismos que experimentan las formas sometidas a un proceso de gramaticalización típico, mientras que los cambios IV) v) y vI) parecen, por el contrario, apoyar un cambio por desgramaticalizacion, ya que sugieren que las formas subjetivizadas pueden debilitar su integración sintáctica y pasar a funcionar como disjuntos y formas autónomas. Vamos a ver más tarde que los seis cambios interactúan de manera complementaria en el cambio verbo > marcador pragmático que enseguida analizaremos, y que es un verdadero problema caracterizar la subjetivización como uno $\mathrm{u}$ otro tipo térico de cambio.

Un aspecto de la subjetivización poco estudiado hasta ahora es la relación

(dirs.), vol. 3, Madrid, Espasa Calpe, 1999, págs. 3993-4050; Fraser, «Pragmatic markers» y "What are discourse markers?», citados en la nota 14; María Antonia Martín Zorraquino y José Portolés, «Los marcadores del discurso», en Gramática descriptiva de la lengua española, I. Bosque y V. Demonte (dirs.), vol. 3, Madrid, Espasa Calpe, 1999, págs. 4051-4213; Salvador Pons, «Los apelativos oye y mira o los límites de la conexión», citado en la nota 15; Schourup, «Discourse markers», citado en la nota 14; Schwenter «Some reflections on $o$ sea: A discourse marker in Spanish», citado en la nota 18; Traugoth, «The role of the development of discourse markers in a theory of grammaticalization" $y$ «The rethoric of counter-expectation in semantic change: A study in subjectification», citados en la nota 15; Amold Zwicky, «Clitics and particles», Language, 61:2, 1985, págs. 283-305.

24 Es esta, posiblemente, la propiedad de las expresiones subjetivas que ha despertado menor atención; aparece comentada en: Adarnson, «A lovely little example. Word order options and category shift in the premodifying string», citado en la nota 22 , quien dedica un breve comentario en la página 57; Bert Cornillie, "The syntax of subjectification in Spanish quasi-modal constructions", Pre-print 198, 2003, Department of Linguistics, K.U. Leuven; Langacker, en «Observations and speculations on subjectivity», citado en la nota 15, habla de «zero syntax»; Verhagen, "The girl that promised to become something': An exploration into diachronic subjectification in Dutchs, citado en la nota 15 , realiza un comentario explícito en la página 204; Company, "Gramaticalización por subjetivización como prescindibilidad de la sintaxis», citado en la nota 11, trata algo más extensamente el fenómeno. 
natural que, a mi modo de ver, existe entre la subjetivización y los últimos tres cambios sintácticos experimentados por las formas sometidas a dicho proceso de cambio: ampliación del alcance de la predicación, fijación y autonomía predicativa y reducción o empobrecimiento de capacidades sintácticas. Es decir, hay poca investigación sobre cuáles son las huellas estructurales formales que deja el enriquecimiento pragmático de las formas que adquieren significados subjetivos.

La hipótesis que sustenta este trabajo es que existe una relación bastante transparente, inversamente proporcional, entre la cantidad de sintaxis que una forma necesita y el grado de significado subjetivo-valorativo que esa forma expresa: no subjetividad (u objetividad) $=$ mayor cantidad de sintaxis, $y$ subjetividad = menor cantidad de sintaxis, al punto de que con frecuencia subjetivización y aislamiento sintáctico van de la mano. Por «cantidad de sintaxis» debe entenderse la capacidad relacional sintáctica de la forma en cuestión, esto es, capacidad para subcategorizar, para tomar modificación y expansión, para ser sustituida y parafraseada por otras formas, etc.

Esto es, si se acepta que la subjetivización implica pérdida de los aspectos descriptivos y referenciales del significado (cambios I y II), lo lógico es pensar que también implique cancelación y pérdida de la sintaxis requerida por esos aspectos descriptivos referenciales. Esta propuesta captura la idea de 'reducción paralela' formulada por Bybee, Perkins y Pagliuca ${ }^{25}$, o el concepto de 'coevolución' de Bybee y Pagliuca ${ }^{26}$. Vamos a ver que, en efecto, todos los marcadores pragmáticos procedentes de verbos en la historia del español sufren una drástica cancelación de la sintaxis usual de esos verbos, al mismo tiempo que un drástico debilitamiento semántico referencial ${ }^{27}$.

Dos causas, ambas complementarias, operan en esta relación entre enriquecimiento pragmático y cancelación de sintaxis, una inmediata, gramatical diacrónica, otra mediata de naturaleza teórica cognitiva:

a) Causa inmediata.--La primera razón es que las formas para llegar a entrar en una predicación subjetiva requieren tiempo, requieren profundidad histórica --por lo general son de documentación más tardía que sus correspon-

${ }^{25}$ The evolution of grammar. Tense, aspect, and modality in the languages of the world, Chicago, The University of Chicago Press, 1994, especialmente págs. 106 y ss.

26 "Cross-linguistic comparison and the development of grammatical meaning", en Historical semantics and historical word-formation, J. Fisiak (ed.), Berlin, Mouton de Gruyter, 1985, págs. 59-83. Una idea similar está formulada en Brinton, Pragmatic markers in English. Grammaticalization and discourse functions, Berlin-New York, Mouton de Gruyter, 1996, en la pags. 250 y ss.

${ }^{27}$ El mismo empobrecimiento, e incluso cancelación sintáctica, se produce en otras categorias, además de en los verbos, cuando adquieren significados subjetivos valorativos: cuantificadores, preposiciones, adjetivos y adverbios; cf. Concepción Company, «Subjectification and syntactic canceltations, en Paths of subjectivity, B. Comillie, C. Canakis y S. Athanasiodous (eds.), Berlin-New York, Mouton de Gruyter, en prensa. 
dientes lecturas objetivas-y ese tiempo acumula desgaste y erosión de la capacidad relacional sintáctica de la forma.

b) Causa mediata.-La segunda razón, de carácter cognitivo, me parece la fundamental: la cancelación y aislamiento sintáctico son una consecuencia natural de un proceso de subjetivización, ya que el hablante o conceptualizador al emitir un enunciado subjetivo no está interesado en hablar del mundo, del evento, ni en describir las entidades que integran ese mundo, sino que sólo está interesado en hablar de cómo él ve el mundo, de aportar sus propias valoraciones sobre el evento. En consecuencia el hablante no necesita sintaxis, o la necesita mínimamente, porque no es necesario hacer explícitos los aspectos descriptivos y referenciales requeridos por las entidades, y por tanto es prescindible toda la sintaxis que sería necesaria para hablar de esas entidades. Esto es, un proceso de subjetivización implica pérdida de los aspectos descriptivos y referenciales del significado objetivo, e implica, lógicamente, prescindibilidad o cancelación de la sintaxis requerida por ese significado objetivo. Una subjetivización es fundamentalmente, desde mi punto de vista, un hecho de prescindibilidad de la sintaxis, y esta dinámica sintáctica coevoluciona a la par con los efectos semánticos ya sefialados. Por lo tanto, subjetivización, debilitamiento referencial, debilitamiento relacional y prescindibilidad de sintaxis van de la mano, al mismo tiempo que subjetivización y enriquecimiento pragmático, vía la codificación de las valoraciones del hablante, van también de la mano.

Es importante aportar aquí una evidencia adicional, que no involucra marcadores discursivos pragmáticos, pero que apunta al mismo proceso de empobrecimiento y/o cancelación de sintaxis como efecto de un proceso de subjetivizacion, concretamente de epistemización. Sandra Thompson en un artículo reciente sobre subordinadas completivas y sus verbos regentes en inglés conversacional ${ }^{28} \longrightarrow$ construcciones denominadas por la autora «ComplementTaking Predicates» (CTP): I know/see/think/guess... (that) she left- muestra que en el uso real la relacionalidad sintáctica de los verbos de conocimiento, del tipo pensar, adivinar, suponer, saber, con su oración subordinada está completamente debilitada, y esas construcciones CTP más que verdaderas oraciones subordinadas dependientes se comportan como fórmulas de carácter epistémico bastante fosilizadas, «stance formulas» (pág. 138), «re-usable fragment schemas» (pág. 137); muestra también la autora que de la gama léxica posible de verbos regentes sólo se actualizan o se hace uso real de unos pocos, que arrojan altísima frecuencia de uso, que esos verbos suelen además muchas veces emplearse solos sin complementación, y que las subordinadas de esos verbos no son realmente predicaciones plenas sino que más bien operan como

28 "'Objects complements' and conversation towards a realistic account», Studies in Langua$g e, 26: 1,2002$, págs. $125-164$. 
frases adverbiales parentéticas epistémicas, con una distribución no necesariamente adyacente a su verbo regente ${ }^{29}$.

Es decir, la epistemización - un tipo de subjetivización- en la subordinación desemboca también en una fuerte pérdida de relacionalidad sintáctica, lo cual apunta a que, cuando intervienen mecanismos valorativos subjetivos, se desnuda de sintaxis incluso una de las zonas relacionales por excelencia, la subordinación ${ }^{30}$. Por tanto, la cancelación de sintaxis que aquí postulo no sería un efecto circular de la creación de marcadores de discurso, sino que parece ser una consecuencia natural de los procesos de subjetivización o epistemización, ya que al parecer la sintaxis se vuelve innecesaria y prescindible.

Pasemos, ahora sí, a mostrar el cambio verbo > marcador discursivo pragmático en el español, a la luz de estos planteamientos.

\section{LA FLEXIBILIDAD CATEGORIAL DEL VERBO EN ESPAÑOL}

La consulta de los corpus electrónicos, así como los datos de habla espontánea, arroja un número no desdeñable de verbos, 17, posiblemente haya más, que en la historia del español evolucionaron en marcadores discursivos pragmáticos. Denominaremos a estas formas marcadores deverbales. Es una zona diacrónica llamativa por su elevada productividad, si se la compara, por ejemplo, con el inglés, que sólo tiene dos o tres verbos con este uso discursivo pragmático ${ }^{31}$. La productividad del español se constata en el hecho de que uno

${ }^{29}$ Literalmente: «Complements with the most CTPs (I think, I guess) override their CTPs to such an extent that they have been reanalyzed as epistemic parentheticals, i.e. as adverbial phrases, which can and do float away from CTP position. These epistemic parentheticals reveal other phonological, prosodic and grammatical properties of epistemic fragments rather than CTPs with clausal arguments. It is reanalysis due to frequencym (pág. 134). La misma idea de baja integración sintáctica, pérdida de relacionalidad y reanálisis en Sandra A. Thompson y Anthony Mulac, «A quantitative perspective on the grammaticization of epistemic parentheticals in Englishs, en Approaches to grammaticalization, E. C. Traugott y B. Heine (eds.), vol. 2, 1991, págs. 313-330.

${ }^{30}$ El mismo efecto de debilitamiento relacional sintáctico puede observarse en español coloquial, en diálogo, con este tipo de verbos, donde más que regir la subordinada, parecen funcionar como formulas epistémicas, situados al final de la oración y hasta cierto punto desvinculados de la subordinada, con una entonación muy sostenida, como una especie de apostilla valorativa respecto de todo lo contenido en la oración previa, la cual, al menos desde un punto de vista estructural, es subordinada de ese verbo, pero semánticamente contiene la información básica: «pues ya no sé qué pasó después del reven, mano, andaban hasta atrás, llegarian a su cantón, supongo" (español de México, habla de adolescentes, reven = reventón, fiesta; cantón = 'casa'); «a ver si ahora si llegan temprano, digo, ¿no?" (español de México, habla culta) (en cursivas se indica la oración «subordinada» y en negritas el verbo «principal regente»),

${ }^{31}$ Brinton, Pragmatic markers in English. Grammaticalization and discourse functions, Berlin-New York, Mouton de Gnyter, 1996, aporta unas pocas expresiones verbales en inglés antiguo y medio; en el inglés actual parece ser que sólo you know y let's go operan próximos a 
de esos cambios, más que una entrada léxica verbal específica individual, constituye una pauta de construcción altamente productiva en la que puede incluirse una lista amplia de verbos, que reproducen un mismo esquema de formacion de marcadores: verbo + clítico dativo: andar $>$ ándale, dar $>$ dale, estar $>$ tate, volar > vuélale, caer > me cae, haber > quihúbole, etc. (véase infra $\S 3.1$ ). Se documenta también, como era esperable, una rica gama de contextos y usos intermedios, donde los verbos despliegan, coexistiendo, tanto un valor referencial debilitado cuanto matices valorativos diversos añadidos, y en muchas de esas construcciones intermedias es diff́cil, si no imposible, decidir si se trata ya de un marcador pragmático discursivo o son todavía empleos metafóricos, aun no plenamente gramaticalizados (véase infra \$ 4).

Es interesante señalar que la flexibilidad categorial del verbo en español para evolucionar en marcador, vía una subjetivización, no sólo se observa en el hecho de que constituyen un número elevado de entradas verbales bases, sino en el hecho de que bastantes verbos dieron lugar a dos, tres y hasta cuatro marcadores discursivos pragmáticos, como es el caso de andar, ver o $i r$. En todos los casos, ambos significados y usos, conservador referencial como verbo e innovador subjetivo como marcador pragmático discursivo, han convivido por siglos, lo cual da sustento a la idea de que el cambio sintáctico es acumulativo, y produce un efecto de estratificación o capas ${ }^{32}$.

El cambio no subjetivo > subjetivo en el verbo es posible porque el verbo es quizá la categoría deíctica por excelencia, y para que se produzca un proceso de subjetivización se requiere una zona categorial que no tenga un valor gramatical a priori, sino que adquiera su valor en el contexto, en el acto de habla, de manera que el hablante pueda manipular creativamente el contexto, y con ello desproveer a las formas de su significado originario, para, simultáneamente, enriquecerlas con sus propias valoraciones; es decir, se requiere una zona fuertemente deíctica para que se produzca una (des)gramaticalización por subjetivización, y el verbo, sin duda, lo es.

En cuanto a la diversificación diatópica de los marcadores deverbales documentados, no todos tienen una extensión dialectal similar: algunos son de uso general en el español: a ver, vaya, oye, oiga, mira (castellano) / mirá vos (español argentino), mira nada más (español mexicano); otros son exclusivos del cas-

marcadores. Posiblemente el hecho de que el inglés sea una lengua de sujeto obligatorio, aunado a una morfología flexiva menos rica, dificulta que los verbos pierdan la estructura exocéntrica predicativa y se decategoricen en marcadores.

${ }^{32}$ Cf. para este postulado de que el cambio sintáctico-semántico es por lo regular acumulativo, el artículo clásico de Jerzy Kuryłowicz, «Sur la nature des procés dits analogiques», Acta Linguistica, 5:1, 1945-1949, págs. 15-38, en su ley 3 (pág. 30), y el más reciente de Paul J. Hopper, «On some principles on grammaticization», en Approaches to grammaticalization, E. C. Traugott y B. Heine (eds.), vol. 1, 1991, págs. 17-36, principio $1^{\circ}$ (pág. 22). 
tellano peninsular: dale, venga, anda, vale; otros son típicos del español americano, bien de solo alguno de los dialectos documentados: ándale, me cae, sepa (México), viste (Argentina), o bien generales para el español americano: dizque; finalmente, otros tienen un ámbito diatópico y/o diastrático mucho más reducido: cucha, velay, de empleo casi exclusivo, al parecer, en Andalucía oriental el primero, o propio de hablantes de tercera generación en zonas rurales el segundo.

En cuanto a la profundidad histórica de estos marcadores discursivos deverbales, algunos se documentan ya en el siglo XII, como es el caso de vaya (véase infra el primer ejemplo de 15b). El CORDE y el LHEM documentan con cierta frecuencia expresiones deverbales subjetivas a partir del siglo XVI, muy frecuentes dizque y tate, y para el siglo $\mathrm{xx}$ se pueden encontrar con facilidad en los tres corpus electrónicos consultados. Sin embargo, es necesario en este punto hacer un comentario precautorio. Es bien sabido en linguística histórica que la ausencia de documentación no significa ausencia de la lengua; pues bien, este principio se aplica plenamente a las expresiones subjetivas en general, y aún más a los marcadores discursivos, ya que estos sólo surgen en la interacción dialógica real de hablante y oyente, de manera que es difícil, si no imposible, documentarlos en la lengua literaria (que no pretenda reproducir expresamente esa interacción), la cual constituye la base del análisis diacrónico, de manera que el establecimiento de la cronología y la profundidad histórica de los marcadores objeto de estudio ofrece serias dificultades.

Listaré primero los verbos, ejemplificando para cada uno de ellos, a manera de par mínimo, los dos extremos del continuum categorial evolutivo: un uso como verbo pleno (ejemplos de a) y el uso innovador subjetivo, como marcador pragmático (ejemplos de b, c, d). Para comodidad del lector, y para obtener una mejor visión global del fenómeno diacrónico estudiado, introduce cada uso el infinitivo del verbo en cuestion, a manera de etiqueta identificadora, en el entendido de que la forma diacrónica base del cambio la constituyen, estrictamente, los ejemplos de $\mathbf{a}^{33}$. Posteriormente examinaré las propiedades gramaticales que en conjunto exhiben estos verbos. El orden de aparición en esa lista refleja una agrupación por clases léxicas, al mismo tiempo que pretende mostrar la amplia gama de clases léxicas verbales que entran en este tipo de cambio: verbos de percepción y entendimiento (6-14), verbos de movimiento (15-21), verbos transitivos que suponen transferencia (22-23), verbos estativos (24-26), y otros cuya adscripción a clases grandes no me fue posible establecer (27-28).

${ }^{33}$ No tomo en consideración usos predicacionales subjetivos que no han alcanzado un estado de univerbación, del tipo quién sabe, o frases hechas del tipo chúpate esa, vete tú a saber, qué le vamos a hacer, qué le hemos de hacer, aunque obviamente constituyen uл ejemplo más del mismo proceso de subjetivización, sin llegar al grado de fosilización y autonomía que exhiben los marcadores discursivos objeto de este trabajo. 


\subsection{Verbos que evolucionan a marcadores discursivos pragmáticos ${ }^{34}$}

(6) $\mathrm{DECIR}>$ dizque

a. ya Plinio, en su Historia Natural, dice que las palmas datileras dan en las costas de España un fruto... (CORDE, s.v. dice, año 1948)

b. Las familias dizque decentes andan desesperadas y nosotros no sacamosun centavo ni pa los frijoles (CORDE, s.v. dizque, 1973) Tenemos dos líneas, una dizque para el internet y la otra normal, y las dos siempre ocupadas

c. - ¿Cómo vivirá esa gente? -Dizque son artistas (CORDE, s.v. dizque, 1970)

(7) ESCUCHAR > cucha

a. lo que te estoy diciendo te lo he repetido mil veces, y nunca me escuchas, haces siempre tu regalada gana

b. ¡Cucha!, decías que no ibas a venir y estás aquí

(8) ofr > oye / oiga

a. díxo que oye missa todos los días de fiesta (LHEM, s.v. ofr, 1771)

b. ¡Oye, pero qué caro es esto!

-Me voy a casa, me cambio mientras me caliento, y a las ocho me voy a casa 'Pepe a correr -iQué bien, oye! (apud Pons Bordería) ${ }^{35}$

c -Debería ir usted a verle -Oiga, oiga, que venga a verme él (apud Martín Zorraquino y Portoless) ${ }^{36}$

(9) SABER > sepa

a. Sepa su magestad que ay neçesydad de sembrar para coger (LHEM, s.v. saber, 1526)

b. - iInicia hoy el curso de locacion? - iSepa la bola! ${ }^{37}$ - ¿Ya llegó el paquete de Estados Unidos? — ¡Sepa!

(10) MIRAR > mira / mirá / mire

a. Fischler, a la derecha, mira el reloj en presencia de A.C. y el ministro irlandés (CORDE, s.v. mira, 2000)

yo no pude pilotar nunca más un Spitfire, mira mis manos, así que me asignaron otras misiones (CORDE, s.v. mira, 2000)

b. Mira, hasta aquí hemos llegado (apud Martín Zorraquino y Portolés) ${ }^{38}$

Pues por eso, yo ni lo... he cogío, yo ni lo he cogío, mira (apud Pons Bordería) ${ }^{39}$

\footnotetext{
${ }^{34}$ Los ejemplos sin referencia entre paréntesis pertenecen a habla espontánea.

35 «Los apelativos oye y mira o los límites de la conexión», pág. 215, citado en la nota 15.

36 «Los marcadores del discurso», pág. 4186, citado en la nota 23.

${ }^{37} \mathrm{El}$ nominal inanimado bola es un empleo metonímico por bola de gente con el significado de 'multitud'; un uso indefinido, esto es, 'cualquiera de la multitud', y a partir de ahí puede inferirse la duda respecto de lo que se sabe.

38 «Los marcadores del discurso», pág. 4182, citado en la nota 23.

39 «Los apelativos oye y mira o los línites de la conexión», pág. 214, citado en la nota 15.
} 
c. ¡Mirá vos, qué interesante!, ni lo pensé

d. Mire, 1995 fue el año en que se registró el menor número de huelgas (apud Martín Zorraquino y Portoles) ${ }^{40}$

(11) VER > a ver

(12) VER $>$ velay ${ }^{42}$

(13) VER > vera(s)

(14) VER > viste

a. El dicho corregidor fue a ver los dichos alixares e, vistos por él los dichos pedimientos..., fizo çiertos abtos (CORDE, s.v. ver, siglo $\mathrm{XV}$ )

ya te digo yo que para entender de arte no basta con ir a los museos y ver cuadros, hace falta entrenamiento y educación de la vista, y del alma, algo más...digo yo

b. Yo siempre tengo razón ja ver si no! (apud Montolío y Unamuno) ${ }^{4 i}$

a. dice se ve y siente arder en vivas llamas (LHEM, s.v. ver, 1812)

b. -Entonces, ¿quién era el asesino, el detective? —jVelay!

a. mira para el cièlo y verás qué luna

b. verás... te cuento, estaba yo paseando tranquilamente cuando aparece mi exnovio, imaginate

c. Verá, eso no es precisamente lo que yo le quería decir

a. y tú, mirame, ¿ya me viste? (LHEM, s.v. ver, 1797)

b. La verdad es un tesoro, que me tiene como a una reina. Te diría que más que un esposo es un esponsor, viste (Periódico La Nación, Buenos Aires, 2003)

Pues no, no sabía qué decir, viste, la situación era tan delicada

Ver es un verbo bastante productivo como fuente de partículas pragmáticas discursivas en el español, con diverso grado de subjetivización y fijación: ¿ves? si no hubieras bebido tanto; ya ves, aquí tirando; vamos a ver ¿qué locura es esta? ${ }^{43}$ En este momento de la investigación, no estoy muy segura de si son usos metafóricos en los que todavía puede entreverse un residuo del significado originario, o son ya marcadores discursivos. La misma incertidumbre con respecto a ciertos usos verbales, proximos a marcadores, que se usan como muletillas, del tipo ime entiendes? o fijate.

40 «Los marcadores del discurso", pág. 4183, citado en la nota 23.

41 *The discourse marker a ver (Catalan, a veure) in teacher-student interaction», Journal of Pragmatics, 33, 2001, págs. 193-208.

${ }^{2}$ Es una expresión cognada con el francés voila. El marcador del español incorpora el verbo ver, ve, un clítico acusativo, lo (la?), y un adverbio locativo aht-y. El Diccionario de la lengua española de la RAE no lo acentua, pero en el español de Andalucía puede oirse también con acento agudo: velár.

${ }^{43}$ Para una lista de empleos discursivos de ver, con distintos grados de lexicalización y subjetivización, puede consultarse el artículo de Montolio y Durán, «The discourse marker $a$ ver (Catalan, a veure) in teacher-student interaction», citado en la nota 41, págs. 195-196. 
(15) R > vaya

(16) $\mathrm{IR}>\left(\right.$ ahilquê) $v a^{44}$

(17) IR > (v)ámos(nos)

a. ven, vamos para afuera (LHEM, s.v. ir, 1802)

b. La' subsecretaría de Egresos de la Secretaría de Hacienda... debe programar pagos por 30 millones de pesos a cuenta de un adeudo por más de mil 214 millones - jÁmonos!, dicen los malosos (Periódico El Financiero, México, 2003)

c. ese nombrecito clave es una cursilada, juna mariconada, vamos!

d. ¡Amos ya!, pero ¿tú qué te has creído?

(18) VENIR > venga a. la neçessidad muy grande que en estas partes ay de que de nuevo vengan de esos reynos de España cantidad de religiosos (LHEM, s.v. venir, 1564)

b. Bueno, venga ya, hombre, ya. Eres un sentimental (apud Salazar) ${ }^{45}$

- ¿Quieres un té o un café? -Venga, un café (apud Salazar)

(19) CAER > me cae a. Al que en ella cae y aun con largo tiempo no se levanta (LHEM, s.v. caer, 1808)

b. Me cae! Con esta gente no se puede tratar

(20) ANDAR > anda a. avjseme v. m. si se usa aca andar a mula los señores letrados (LHEM, s.v. andar, 1583)

b. Anda, calla (LHEM, s.v. andar, 1576)

¡Anda ya!, ni tú te crees eso

44 No he podido encontrar la graficación de aiva; no la traen los diccionarios. Creo que es un adverbio locativo ahi $+i r$, como parecería ser lo logico, ya que un verbo locativo se construye con un argumento locativo; sin embargo, pudiera ser una palabra a partir de la interjección ay: ayva, focalizando el nuevo valor pragmático intensivo. Ir es posiblemente el verbo más flexible para formar marcadores pragmáticos sin intervención de clítico dativo; ha formado, incluso, una locución sustantivada: el no va más: esto es el no va más de la moda.

${ }^{45}$ Cf. Silvia Salazar Urrestarazu, «Venga: A discourse marker with illocutionary force», ponencia lefda en el 6th Annual Ohio State University Graduate Student Symposium on Hispanic and Luso-Brazilian Literature, Linguistics and Culture, 2003. 
(21) ANDAR > ándale / ándele

(22) DAR > dale a. que ffue animal bivo, et cubierto de casco, con muchos pies, que anda a todas partes (CORDE, s.v. anda, 1250-1270)

b. ¿No qué no, cabrón? Ándale, pa' que sientas, ¡ojete! (CREA, s.v. ándale)

c. - ¿Eso es todo el problema? - Ándele, eso mismo

(22) DAR > dale

\begin{abstract}
a. Et por esta carta pedimos merçet a nuestro señor el rrey e a nuestra señora la meyna que le quiera fazer merçet. $\mathrm{E}$ dale carta de perdón (CORDE, s.v. dale, 1180)

b. ¡Y dale! ¿Pero no ves tá lo que cuesta mantener una familia? (CORDE, s.v. dale, 1928)

¡Y dale con abrir la puerta! cómo fastidias
\end{abstract}

La construcción verbo + clítico dativo en español, como ya señalé, es sumamente productiva para formar marcadores pragmáticos. Además de la base intransitiva de (21) y la transitiva de (22), otros muchos verbos, transitivos e intransitivos, en su gran mayoría estos últimos, pueden adquirir significados subjetivos vía este patrón construccional: volar $>$ vuélale, picar $>$ pícale, entrar $>$ éntrale, haber $>$ quihubo(le), meter $>$ métele, tomar $>$ tómele, chingar $>$ chingale, correr $>$ córrele, pensar $>$ piénsale, apurar $>$ apúrale, etc., o ligeramente distinto, pero manteniendo la misma pauta, hacer $>$ no le hace ${ }^{46}$. Ejemplifico con dar y andar porque son sin duda los marcadores deverbales de este tipo con mayor frecuencia, el primero en el español peninsular, el segundo en el español de México y español de chicanos (véase infra \$ 4.1 para un análisis del proceso diacrónico sintáctico-semántico de subjetivización de este tipo de construcción). También en otros verbos intervienen dativos, esta vez reflexivos, para la formación de marcadores deverbales, tal es el caso de tate, me cae o (v)ámonos.

(23) TOMAR > toma (ya) a. el alcayde Salazar casy toma la boz de Hernando Cortés y por propias cosas suyas, las suyas (LHEM, s.v. tomar, 1526)

b. Lilián va a cantar en una sala rociera que se llama $\mathrm{Al}$ gas de Cádiz, toma ya, cosa ecológica y alimenticia donde las haya (CE, s.v. toma, 1988)

En México se le nota más a González el cantinfleo, como eso que ha dicho que Aznar dirá lo que le digan que tiene que decir, toma ya! (CE, s.v. toma, 1997)

${ }^{46}$ Cf. para esta pauta discursiva subjetiva de verbo + clítico dativo, Concepción Company, «Reanálisis en cadena y gramaticalización. Dativos problemáticos en la historia del español», Verba. Anuario Galego de Filoloxía, 29, 2002, págs. 31-69; Rena Torres Cacoullos, «Le: From pronoun to intensifier», Linguistics, 40:2, 2002, págs. 285-318; Rena Torres Cacoullos y Esteban Hernández, «A trabajarle: La construcción intensiva en el español mexicano", Southwest Joumal of Linguistics, 18:2, 1999, págs. 79-100. 
(24) ESTAR $>$ tate A $^{47}$ a. Anda ya, déjate eso, estate sosegado. Bien es que te llamen cuerdo sufrido (CORDE, s.v. estate, 1604)

b. vino a caer dentro de una acequia, y viéndome çapuçado, dixe entonces: ¡Tate!, por mí lo decían (CORDE, s.v. tate, 1545-1665)

(25) SER $>$ o sea

a. no tenga $v$. merced a novedad que yo sea contra mi madre (LHEM, s.v. ser, 1772)

-Sólo fue el noticioso, marido - Sea lo que sea, mujer, ya sabes mi criterio (CE, s.v. sea, sin fecha)

b. Creo que el menú es un poco caro, o sea (apud Schwenter) ${ }^{48}$

ahí mismo me entere de que encima de todo, o sea, se ocupaba de ese asunto, que te juro, ay no sé... (CE, s.v. o sea, sin fecha)

(26) VALER $>$ vale

a. Vale caro el pan (LHEM, s.v. valer, 1572)

Vale muy bien porque es hombre muy aplicado (LHEM, s.v. valer, 1575)

b. Te mando el libro por correo ¿vale? -Muy bien, vale (apud Martín Zorraquino y Portolés) ${ }^{49}$

(27) JODER > joder/joer a. joder es verbo transitivo o intransitivo, según: irse a joder o joder a Pepita (CREA, s.v. joder, 1994)

b. Vaya gustazo, joder. Y encima el Castello se permite... (CREA, s.v. joder, 1994)

¡Joer!, a ver si entiendes, que no te enteras

$(28)^{50}$ ARREAR > arrea

a. De todos los extremos de la vega llegaban chirridos de ruedas, canciones perezosas interrumpidas por el grito que arrea a las bestias (CORDE, s.v. arrea, 1898)

b. el nombre es lo que más nos gusta, tiene musicalidad: Princesa de las canzonetistas, ¡arrea! (CORDE, s.v. arrea, 1916)

haz tajadas de ese tarugo, muchacho, que ahora viene como de periya aqueyo de jarrea, Manolo! (CORDE, s.v. arrea, 1850)

\footnotetext{
${ }^{47}$ Es conocida la conflictiva etimología de la voz tate. Corominas (Diccionario critico etimológico castellano e hispánico, con la colaboración de J. A. Pascual, Madrid, Gredos, 19831985 , s.y. tate) se inclina por una etimologia no verbal, y considera que se trata de una repetición expresiva de $t a$, descartando el posible origen predicativo de esta forma, a saber, un clítico dativo de 2." persona fusionado a un verbo y este, a su vez, erosionado fonológicamente: tate < estate < estate quieto, estate aht. Sin embargo, el hecho de que la expresión jtate! tenga afinidad estructural con los otros dativos intensivos que aqui analizo y muestre una pauta de vaciado referencial, pérdida de relacionalidad y reuso pragmático del dativo otorga un fuerte apoyo al origen oracional de esta exclamacion.

48 «Some reflections on o sea: A discourse marker in Spanish", pág. 865, citado en la nota 18.

49 *Los marcadores del discurso", pág. 4170, citado en la nota 23.

${ }^{50}$ Es posible que hala pudiera considerarse un último marcador discursivo deverbal en esta lista, a partir del verbo halar / jalar. Corominas (Diccionario critico etimológico, s.v. hala) descarta esta relación, establecida por la Academia en ediciones del siglo XIX. Sin embargo, el propio Corominas formula otra relación marcador-verbo, esta vez en sentido inverso: a partir de hala se habría formado el verbo jalear.
} 
El cuadro 1 a continuación expone de manera concentrada la lista de lexemas verbales documentados que dan origen a marcadores: 17 , y el número de marcadores: 25. Puede verse que en la mayoría se mantiene una relación de uno a uno, pero algunos verbos han dado lugar a dos, tres y hasta cuatro marcadores, lo cual es muestra de que se trata de un patrón evolutivo bastante productivo para la categoría verbo en el español.

\begin{tabular}{|l|l|}
\hline \multicolumn{2}{|c|}{ CUADRO 1 } \\
\multicolumn{2}{|c|}{ Relación cuantitativa de verbos y marcadores } \\
\hline LEXEMA VERBAL & NÚMERO DE MARCADORES \\
\hline decir & 1 \\
escuchar & 1 \\
oír & 1 \\
mirar & 3 \\
ver & 4 (posiblemente más) \\
saber & 1 \\
ir & 3 \\
venir & 1 \\
andar & 2 (pauta productiva) \\
dar & 1 \\
tomar & 1 \\
estar & 1 \\
ser & 1 \\
caer & 1 \\
valer & 1 \\
joder & 1 \\
arrear & 1 \\
TOTAL 17 & 25 \\
\hline
\end{tabular}

\subsection{Propiedades gramaticales de los verbos que originan marcadores}

El conjunto de los verbos que evolucionan a marcadores admite una caracterización gramatical común. Examinaré en primer lugar el tiempo, el modo y la clase de verbo, a continuación la estructura intema y distribución, después su semántica, para abordar finalmente la frecuencia de uso y el mecanismo de cambio involucrado en el porceso verbo > marcador.

- Tiempo.-Se (des)gramaticalizan preferentemente en presente, indicativo o subjuntivo, o en infinitivo, que en conjunto se pueden caracterizar como tiempos no pretéritos y no télicos, y el infinitivo, en sí mismo, como un no tiempo. Hay, por tanto, un claro debilitamiento de la deixis temporal de los verbos que entran en este proceso. El hecho de que la fuente del cambio sea atélica puede 
interpretarse como que se deja la acción abierta para que pueda ser reelaborada pragmáticamente. Un tiempo verbal pretérito no es fuente de marcadores pragmáticos en el español: *dióle, ${ }^{*}$ me cayó, *ahí fue, ${ }^{*}$ miró, ${ }^{*}$ dijo ${ }^{51}$.

- Modo.-Los marcadores discursivos deverbales tienen cierta flexibilidad modal, pero se (des)gramaticalizan mayoritariamente a partir del imperativo y, en segundo lugar, del subjuntivo: ándale, vuélale, mira/mire, dale, vaya, venga, o sea, sepa, etc. De los 25 marcadores deverbales identificados en este trabajo, 16 tienen como base un imperativo o un subjuntivo. Esta preferencia puede interpretarse como que el oyente y el hablante, que están involucrados en el significado de imperativo y subjuntivo, pasan a estar perfilados (en el sentido del término en la gramática cognitiva), esto es, en el empleo referencial de esos verbos hablante y oyente estarían codificados en fondo, en el uso subjetivo pasan a estar perfilados o puestos de relieve. En general, puede postularse que los verbos en su evolución a marcadores debilitan y pierden deixis temporal, refuerzan la deixis aspectivá modal y ganan deixis discursiva pragmática. Puede establecerse el siguiente camino diacrónico: deixis temporal $>$ deixis aspectiva modal > deixis pragmática.

- Clase de verbo.-Una buena parte de estos marcadores discursivos deverbales procede de verbos de movimiento que suponen desplazamiento hacia una meta locativa, ir, venir, andar, caer, o de verbos estativos locativos, estar, o de verbos transitivos, varios de ellos de transferencia, física o metafórica, que implican un objeto, meta última de la transitividad, dar, oír, escuchar, ver, es decir, ambas clases de verbos tienen en comán el hecho de codificar una meta. Lo que creo que hacen los usos subjetivos es debilitar la meta sintáctica y fortalecer una meta pragmática, hablante u oyente, que se involucra en el evento; en otras palabras, los marcadores deverbales mantienen, reinterpretada, vestigios de la estructura argumental originaria. El hecho de que algunos marcadores integren en su estructura adverbios locativos, velay, ahiva, o una preposición locativa directiva: $a$ ver, es muestra, a mi parecer, de que incorporan la meta del movimiento en su significado. Un concentrado importante de marcadores deverbales, como ya señalé, gira alrededor de verbos de percepción y conocimiento, es decir, capacidades inherentes del ser humano: saber, decir, escuchar, ofr, ver, mirar.

- Estructura.-La base del cambio puede ser el verbo solo: anda, vaya, o una construcción: verbo + afijo-partícula: ándale, dizque, o incluso una construcción verbal más compleja: (preposición) + verbo + (clítico) + (adverbio): ahiva, velay, a ver. Cualquiera sea la base, se produce en todos los casos un debilitamiento e incluso cancelación de la capacidad distribucional y argumen-

51 Dos son las excepciones que confirman la regla: quihúbole, quihubo, del español de México, y viste, del español de Argentina, ambos (des)gramaticalizados en pretérito. 
tal originaria de los verbos, y se produce univerbación en los casos en que la base del cambio es una construcción; algunos pueden tomar adverbios, pero con restricciones, como el caso de vale. El camino diacrónico puede caracterizarse como un carnbio con la siguiente dirección: alta relacionalidad > débil relacionalidad > cero relacionalidad, ya que pierden complementación, no pueden negarse, no pueden tomar adverbios en su gran mayoría, etc. Subjetivización y cancelación de sintaxis van a la par.

Pueden dejar residuos formales de su complementación originaria: a ver, dizque, andale, dale, y dale con eso, tate, pero en esos casos se ha producido, como digo, un proceso de coalescencia que opaca las relaciones entre las dos formas y el constructo todo parece funcionar como una unidad: ahiva, dizque, $a v^{5}{ }^{52}$. Su estatus como marcadores supone pérdida de las altemancias flexivas verbales originarias, si bien algunos muestran alternancia de persona: miral mire, oyeloiga, andalel andele, lo cual indica que su carácter verbal persiste, persistencia del valor etimológico originario que es típica de los procesos de gramaticalización ${ }^{53}$. Puede darse concordancia entre la morfología de persona del verbo-marcador y el referente: oiga usted, oye tú, aunque pueden documentarse casos esporádicos de discordancia: “ye tías, os estaba buscando, tía» (apud Pons). ${ }^{54}$ En opinión de Pons, tales residuos morfologicos y sintácticos serían muestras de una gramaticalización parcial. Algunos de ellos han llegado a lexicalizarse y constituir fórmulas interjectivas, tate, velay, con entrada propia en los diccionarios. Se produce también en muchos de ellos un proceso de erosión fonológica, que resulta en acortamiento de la estructura originaria: vámonos > ámonos, joder $>$ joer, escucha $>$ cucha, of $>$ 'ye, etc., erosión que es típica de los procesos de gramaticalización, definida de la manera tradicional.

- Distribución.-Los marcadores discursivos no se integran en la estructura de constituyentes de la oración; se sitúan, por lo regular, en inicio absoluto del enunciado, como se aprecia en la mayoría de los ejemplos de las series (b) o (c) del apartado anterior, $\$ 3.1$, o también, menos frecuentemente, en final absoluto, como en (8b), (10b) u (11b). Ambas posiciones extremas en la cadena sintágmática son indicio de que han ampliado su alcance predicativo y de que, por lo tanto, se han subjetivizado (cf. supra la característica IV en §2). Pueden aparecer también en posiciones interiores, pero en estos casos aparecen aislados por pausas, lo cual es muestra de la pérdida de relacionalidad sintáctica, típica de la subjetivización. Una propiedad de los marcadores discursivos

\footnotetext{
52 Prueba de ello es que muy frecuentemente en escritura descuidada a ver se grafica aver.

53 Cf. Paul. J. Hopper, «On some principles on grammaticization», citado en la nota 32, principio $4^{\circ}$ (pág. 28).

34 «Los apelativos oye y mira o los límites de la conexión», pág. 215, 217, citado en la nota 15 .
} 
señalada en la mayoría de estudios especializados ${ }^{55}$ es que suelen acumularse, bien, muy frecuentemente, el mismo marcador se duplica, como se aprecia en (29a), o bien aparecen varios de ellos en concatenación, cada uno de ellos matizando un aspecto pragmático distinto, como en (29b).

(29) a. -Ven, chola, dónde te escapas - Oye, oye, qué te pasa (Vargas Llosa) Vaya, vaya, con que escondiéndote, eh

b. Hombre, mira, esto que cuentas es, vamos, muy sorprendente, oye Oye, mira, que ha venido un chico a dejar tu bolso

- Semántica.-Una elevada polisemia caracteriza a los verbos que se recategorizan como marcadores. Son verbos de un significado general, es decir, verbos de baja elaboración semántica, con gran flexibilidad por tanto para aparecer en diferentes tipos de contextos, lo cual hace que se recarguen de nuevos significados permeados por esọs nuevos contextos. Quizá las únicas excepciones en la lista de (6) a (28) son joder y arrea. Verbos de significado muy específico, los denominados de alta elaboración semántica, como tararear, escudriñar, susurrar, cuchichear, transferir, acostar(se), enterrar, etc. no entran en el español en procesos de (des)gramaticalización, es decir no sufren pragmatización, ni tampoco auxiliarización.

- Frecuencia.-Los verbos que evolucionan en marcadores discursivos son los de empleo más frecuente en el español. Lo interesante es que esos mismos verbos son los que experimentan procesos de gramaticalización, entendida a la manera tradicional; son, por ejemplo, los verbos típicos que entran en procesos de auxiliarización, además de mantener empleos como verbos plenos: haber: auxiliar (hubo cantado, cantaré < cantare habeo), existencial (hubo fiestas), marcador (quihubole); ser: auxiliar (sea hecho), marcador (o sea), andar: auxiliar: (anda diciendo), marcador (anda, ándale), ir: auxiliar (va a comprar), marcador (ahiva, qué va), etc. Parece producirse una gran paradoja, ya que los mismos verbos que se gramaticalizan y se integran en la estructura gramatical son los que se independizan de la gramática y se vuelven predicaciones autónomas.

El cuadro 2 abajo contrasta las frecuencias de empleo de algunos de los verbos que generan marcadores deverbales con las frecuencias de uso de algunos verbos muy específicos de alta elaboración semántica. Para los primeros el conteo es restringido, en el sentido de que sólo contabilizo la forma verbal que

${ }^{55}$ Cf. Alonso-Cortés, «Las construcciones exclamativas. La interjección y las expresiones vocativas»; Martín Zorraquino y Portolés, «Los marcadores del discurso», ambos citados en la nota 23; Pons, aLos apelativos oye y mira o los limites de la conexión", citado en la nota 15. Los ejemplos de (29) están tomados de estos dos últimos trabajos, pág. 4185 y pág. 220, respectivamente. 
origina el marcador, para los segundos, el conteo es general, ya que se contabilizan todas las ocurrencias del paradigma verbal. El conteo está realizado sobre la suma del Corpus diacrónico del español (CORDE) de la RAE y sobre el Léxico histónico del español de México (LHEM) en todas las graficaciones posibles, para todos los siglos documentables. Puede verse la enorme diferencia de uso entre ambos tipos de verbos, los primeros son frecuentísimos, los segundos escasísimos, no obstante que para estos últimos se empleó un criterio armplio -todo el paradigma-, y puede verse que su frecuencia no alcanza siquiera la de los verbos menos frecuentes de la columna de la izquierda.

\begin{tabular}{|c|c|c|c|}
\hline \multicolumn{4}{|c|}{$\begin{array}{c}\text { CUADRO } 2 \\
\text { Contraste de frecuencia de uso en verbos }\end{array}$} \\
\hline \multicolumn{2}{|c|}{$\begin{array}{l}\text { VERBOS QUE ORIGINAN } \\
\text { MARCADORES }\end{array}$} & \multicolumn{2}{|c|}{$\begin{array}{c}\text { VERBOS DE ALTA ELABORACION } \\
\text { SEMANTICA }\end{array}$} \\
\hline $\begin{array}{l}\text { está } \\
\text { sea } \\
\text { dice } \\
\text { ver } \\
\text { va } \\
\text { da } \\
\text { toma } \\
\text { vaya } \\
\text { vale } \\
\text { vamos } \\
\text { venga } \\
\text { anda } \\
\text { sepa }\end{array}$ & $\begin{array}{r}141702 \\
120348 \\
107391 \\
81790 \\
55848 \\
53475 \\
14691 \\
12820 \\
12317 \\
11888 \\
9886 \\
8937 \\
6689\end{array}$ & $\begin{array}{l}\text { forzar } \\
\text { acostar/acostarse } \\
\text { revolotear } \\
\text { cuchichear }\end{array}$ & $\begin{array}{r}1596 \\
1419 \\
190 \\
88\end{array}$ \\
\hline
\end{tabular}

Se ha señalado en la bibliografía sobre cambio lingüístico y sobre gramaticalización que la frecuencia de uso de ciertas palabras, expresiones o pautas tiene siempre un impacto en la estructura gramatical, y que la repetición lieva a emancipación, de ahí que la esencia de la lengua es ser ritualizada y repetitiva ${ }^{56}$; pues bien, tal impacto se observa cabalmente en el caso de los verbos

36 Cf. Joan L. Bybee, Phonology and language use, Carnbridge, Cambridge University Press, 2001, especialmente págs. 9-13, varios de los trabajos reunidos en Bybee y Hopper (eds.), Frequency and the emergence of linguistic structure, Amsterdam, John Benjamins, 2000; André Martinet, Economie des changements phonétiques. Traité de phonologie diachronique, Berne, A. Francke, 1970 [1955], cap. 1. 
que nos ocupan: son los más frecuentes del español, y son los que se gramaticalizan y también se desgramaticalizan, en cuanto que se emancipan de la estructura sintáctica, quedando libres para cubrir funciones pragmáticas (así establecido como dos cambios por el momento, a reserva de valorar en $\S 5$ si se trata o no de un mismo tipo de cambio).

- Mecanismo de cambio.-En todos los casos se produjo una descategorización como verbos plenos y una recategorización como marcadores; el mecanismo que permitió la recategorización fue un reanálisis: verbo > marcador pragmático-discursivo, vía el debilitamiento referencial del significado originario de los verbos y su enriquecimiento pragmático en situaciones discursivas específicas. Lo anterior requiere una matización: dado que la (des)gramaticalización no puede ser definida indepenđientemente del contexto, es mejor caracterizar el cambio como reanálisis de la construcción, más que como reanálisis del verbo. Por tanto, el cambio verbo > marcador comparte con la gramaticalización tradicional el mecanismo básico del proceso de cambio: reanálisis.

- Alcance de la predicación.-Se produce en todos los casos un cambio de significado externo-referencial > significado interno-subjetivo; todos los verbos dejan de operar como núcleos de predicado, ampliaron el alcance de la predicación y operan en un nivel extraproposicional, aislados por pausas del resto del contexto en que aparecen, formando una predicación autónoma, es decir, pasaron del nivel proposicional > extraproposicional. Su funcionamiento fuera de la estructura sintáctica nuclear es definitoria de su nuevo estatus categorial como marcadores, y es una propiedad definitoria, como vimos, de la subjetivización.

- Significado subjetivo.-De los marcadores discursivos deverbales identificados, la mayoría tiene un significado esencialmente subjetivo, el hablante aporta su valoración y punto de vista sobre el evento o sobre lo comunicado por su interlocutor: dizque, toma, vale, ahiva, qué va, cucha, mira, mirá, a ver, sepa, velay, oye, (v)amos(nos), vaya, dale, tate, o sea, me cae, arrea, algunos son fundamentalmente intersubjetivos, invitan o involucran al oyente en el evento, es el caso de la mayoría de los marcadores que se construyen con la pauta verbo + clítico dativo: vuélale, apúrale, córrele, etc., y algunos otros pueden operar en las dos perspectivas: venga, ándale.

- Entonación.-Un correlato de la autonomía predicativa es que todos los marcadores discursivos deverbales llevan una entonación sostenida ascendente, que los diferencia de sus verbos base, los cuales soportan una entonacion ascendente-descendente. 
4. EL, PROCESO DIACRÓNICO DE SUBJETIVIZACIÓN VERBO > MARCADOR. DOS ESTUDIOS DE CASO

En este apartado selecciono dos verbos, uno transitivo y uno intransitivo, con el fin de ejemplificar los contextos de cambio que posibilitan el proceso diacrónico de subjetivización verbo > marcador discursivo. Dado que, como ya hemos señalado, el cambio sintáctico es acumulativo, en el español actual conviven todas las etapas evolutivas, de manera que la seriación en (a), (b), (c), etc., es sólo un dispositivo metodológico con el fin de ejemplificar el proceso evolutivo experimentado por la construcción. Se hace patente en el proceso de cambio que cuando los verbos adquieren significados valorativos subjetivos cancelan su distribución y complementación usual y pierden su relacionalidad sintáctica, es decir, prescinden de la sintaxis.

4.1. ANDAR $\rightarrow$ anda $>$ ándale. Verbo pleno de movimiento $>$ marcador discursivo (inter)subjetivo intensivo de exhortación y confirmación

(30) a. De que Blasillo ande al escuela me e bolgado mucho (LHEM, s.v. andar. 1568)

Asta yr a dar a la mar y andar a la mar del sur (LHEM. s.v. andar, 1620)

b. el rregimjiento del mey es que non ande por la çibdat si non caualgando (CORDE, s.v. ande, 1419-1432)

que tirase a un pajaro que anda por alli (LHEM, s.v andar, 1630)

¿qué cree, que uno anda aquí por su puro gusto? (CORDE, s.v. anda, 1916)

c. La justicia no sé cómo se anda (LHEM, s.v andar, 1525) Esta señora no se anda con bromas (CORDE, s.v. anda, 1873)

d. Ya le anda del baño al nin̆o Les anda por terminar el asunto ¿no te anda de hambre? (CREA, s.v. anda, 1995)

e. Dime más cosas, ándale

Y al ver a Buenaventura bien sport, le dio un tirón a su corbata y ordenó a uno de sus ayudantes: «iándale, vete por otra camisa y una chamarna! (Periódico El Financiero junio 2001)

f. $-i$ Y eso es todo el problema? - Andale, exactamente eso ¿y te parece poco?

Los ejemplos de (30) muestran un continuum de debilitamiento argumental progresivo del verbo y, por tanto, una progresiva cancelación de sus posibilidades sintácticas, a la par que un debilitamiento del significado referencial etimológico de movimiento, y una progresiva ganancia de significados valorativos. En (30a) aparece un empleo no subjetivo de andar: funciona como verbo pleno de movimiento, toma un sujeto animado humano, en papel semántico de 
agente y un argumento meta locativa, el agente se desplaza volitivamente hacia la meta locativa.

En (30b) la meta locativa directiva se ha debilitado: es sustituida o bien por una locación estativa, aquí, o bien una locación sin ninguna meta específica involucrada, por la çibdat, por alli, lo cual aminora el significado de movimiento o desplazamiento del verbo. En (30c) la concurrencia de un clítico reflexivo hace que la meta del movimiento sea el propio sujeto, de modo que se cancela la aparición de un argumento locativo y, por tanto, el verbo, carente de ese argumento locativo, debilita completamente su significado de movimiento, y adquiere nuevos significados aspectivos.

El carácter pleno del verbo en los ejemplos de (30a) se corrobora en el hecho de que es sintácticamente flexible: puede ser sustituido por otros tiempos: anduvo, anda, y puede ser parafraseado por verbos de movimiento semánticamente afines: vaya / camine al escuela, camine / vaya a la mar del sur, puede ser negado: no ande a la escuela, puede tomar complementación adverbiol: ande con gusto a la escuela, etc. Esa flexibilidad sintáctica se debilita a partir de los ejemplos de (30b).

Los ejemplos de (30b) y (30c) son los contextos que, a mi modo de ver, constituyen el puente entre la lectura no subjetiva de (30a) y la fuertemente subjetiva de (30ef). Los ejemplos de (30d) exhiben ya un significado subjetivo: no existe un sujeto sintáctico, la meta locativa es sustituida por una meta abstracta, un ser humano, al niño, a ti, cuya referencia aparece duplicada mediante un clítico dativo afijado al verbo, el clítico es todavía un pronombre ya que ancla su referencia en el nominal. El verbo muestra en esta etapa ya un inicio de rigidización sintáctica porque únicamente puede aparecer en tercera persona de singular, anda, sólo el clítico dativo puede variar en persona y entre singular y plural, acorde con su caracter de anáfora, como se ve en los dos ejemplos de (30d): te anda, le anda, les anda.

Los ejemplos de (30e) y (30f) sólo admiten una interpretación subjetiva, muestran la forma ándale como marcador deverbal, intersubjetivo en (30a) y subjetivo en (30b). El verbo más el clítico dativo forman una expresión fija, una predicación autónoma, que debe aparecer sola, no hay posibilidad de construirse con algún otro constituyente. El verbo ya no significa movimiento, y por ello puede concurrir con otro verbo de movimiento, vete, como se ve en (30e), lo cual indica que se ha debilitado enormemente el significado referencial etimológico originario de andar. El clítico dativo integrado en este marcador discursivo es invariable, siempre $l e$, o en otras palabras carece de número porque ya no es una anáfora y ya no tiene, en consecuencia, función referencial alguna. El constructo verbal todo se vuelve también una construcción invariable, que se sitúa, por lo regular, al inicio de la oración, indicando con ello 
que la nueva expresión adquirió un alcance predicativo extraoracional, ampliación de alcance que es típica de los cambios por subjetivización ${ }^{57}$. Se cumplen, por tanto, en este cambio todas las propiedades de la subjetivización vistas en el apartado 2: ampliación de alcance, fijación, autonomía, debilitamiento de significado referencial y pérdida del control agentivo del sujeto.

La nueva construcción está conceptualmente y estructuralmente relacionada con el antiguo verbo; en un nivel mucho más abstracto, el marcador andale preserva la estructura argumental originaria, lo cual es prueba de que las formas mantienen por siglos su valor etimológico, efecto, que corno dijimos, se conoce como persistencia. En efecto, el clítico dativo preserva, aunque debilitado, su valor semántico básico de meta, un locus meta, pero esta vez una meta pragmática; en estas construcciones se elimina el objeto meta gramatical del clítico dativo, para incorporar un participante pragmático, hablante u oyente, que de alguna manera se convierte en la meta pragmática del evento todo. El valor de la construcción, como señalan Torres Cacoullos y Hernández ${ }^{58}$, es de un «significado intensivo, en el sentido de que pone en relieve la situación verbal misma... el le enfoca la acción en sí», y desenfoca al anterior argumento sintáctico, meta o receptor, objeto indirecto. La referencia, que en un empleo conservador etimológico de le está en el constituyente de la oración, pasa a estar en el evento completo, vía el debilitamiento referencial del clítico y del verbo con el que entra en construcción. En otras palabras, se podría resumir la caracterización de este tipo de dativos diciendo que cancelan el argumento sintáctico-gramatical para focalizar un argumento pragmático. En cuanto al verbo, puede decirse que mantiene su significado de movimiento, pero ahora el desplazamiento es metafórico; la meta y desplazamiento espaciales sintácticos etimologicos son sustituidos en las construcciones innovadoras por un desplazamiento mental y una meta pragmática ${ }^{59}$. La baja elaboración semántica de este verbo coadyuva, sin duda, al debilitamiento referencial y abstracción de la meta que estos verbos sufren al entrar en construcción con tales dativos.

Como los denomina Torres Cacoullos ${ }^{60}$ son «dativos intensivos». El constructo en su totalidad, verbo+clítico, funciona como una frase verbal que intensifica la acción significada por el verbo, con la cual el hablante o bien valora el significado global del evento, un marcador de subjetividad (30f), o bien exhorta al oyente, el otro participante del acto de habla, a involucrarse en el evento, un marcador de intersubjetividad (30e).

${ }^{57}$ Cf. los artículos ya citados de Tabor y Traugott, «Structural scope expansion and grammaticalization» de 1998, y de Company «Granaticalización por subjetivización como prescindibilidad de la sintaxis", en prensa.

${ }^{38}$ Cf. «A trabajarle: La construcción intensiva en el español mexicanom, Southwest Joumal of Linguistics, 18:2,1999, págs. 79-100, en particular la pág. 81 .

59 Cf. el artículo ya citado de Langacker, «Subjectification», pág. 327.

${ }^{60} \ll$ Le: From pronoun to intensifier», Linguistics, 40:2, 2002, págs. 285-318. 
Diacrónicamente, la construcción puede caracterizarse como un debilitamiento referencial, e incluso un vaciamiento referencial, del pronombre dativo, al mismo tiempo que como un enriquecimiento pragmático, ya que el dativo adquiere un significado valorativo intensivo. Tal vaciamiento referencial supuso sólo un paso más, en mi opinión, de un largo proceso de debilitamiento referencial iniciado ya en tres cambios previos experimentados por el pronombre dativo: 1) el primer cambio fue la flexibilización de las características léxicas del objeto indirecto, originariamente + humano, y la generalización de la duplicación del OI a todo tipo de indirectos, incluso no humanos: le puse el mantel a la mesa; 2) el segundo cambio que abon6 el camino para la creación de dativos pragmáticos fue la posterior despronominalización del clítico dativo al perder concordancia plural y reanalizarse como una marca de concordancia objetiva: hay que restarle importancia a los problemas; 3) el tercer cambio, ya presente en la lengua latina, que debió coadyuvar a la generación de dativos pragmáticos fue el empleo creciente de la marca de datividad en posiciones no argumentales, los denominados dativos éticos: no le come bien las verduras el bebé, me sacó diez la niña. Se trata, según creo, de un reanálisis en cadena del dativo, a saber: 1: pronombre referencial pleno, argumental y no argumental $\rightarrow$ 2: flexibilización semántica del dativo $\rightarrow 3$ : extensión y generalización de la duplicación $\rightarrow$ 4: pérdida de concordancia-marca sintáctica de concordancia objetiva $\rightarrow 5$ : marca pragmática valorativa ${ }^{61}$.

El análisis que acabamos de realizar cabe, según creo, para todos los marcadores deverbales que incorporan un clítico dativo, como dale, tate, (v)ámonos, además de todos los construidos bajo la pauta de ándale: dale, bríncale, vuélale, pícale, etc.

4.2. SABER $\rightarrow$ sepa $>$ sepa. Verbo transitivo pleno $>$ marcador discursivo de desconocimiento y/o desinterés

(31) a. Sepa su magestad que ay negesydad de sembrar para coger (LHEM, s.v. saber, 1526)

Conviene también que el architecto sepa la sciencia de medicina por las inclinaciones del cielo (CORDE, s.v. sepa, 1582)

Por amor de Dios no lo sepa el padre prior (LHEM, s.v. saber, 1630)

b. Para que se sepa que en todo lo bueno te hallas (CORDE, s.v. sepa, 1729) - ¿Se puede decir así? -Yo, que sepa, no

c. - Inicia hoy el curso de matemáticas? - iSepa la bola!

d. - ¿Ya llego el paquete de Estados Unidos? - ¡Sepa!

${ }^{61}$ Para la evolución diacrónica detallada de este reanálisis múltiple, remito a mi articulo «Reanálisis en cadena y gramaticalización. Dativos problemáticos en la historia del espafiol», Verba. Anuario Galego de Filoloxia, 29, 2002, págs. 31-69. 
Puede verse en esta serie de ejemplos que el verbo pleno saber (31a) se desprovee totalmente de su sintaxis y su capacidad argumental al entrar en un proceso de subjetivización (31cd). En (31a), saber funciona como un verbo monotransitivo normal y muestra su capacidad argumental al completo: toma un sujeto nominal, su magestad, el architecto, el padre prior, y toma también un objeto directo, ya sea nominal u oracional, en el papel semántico de tema. En su empleo referencial transitivo, el verbo es sintáctica y semánticamente flexible, la forma verbal es sustituible por otros tiempos y puede ser parafraseada por otros verbos semánticamente próximos: sabrá vuestra majestad, supo el padre prior, conozca vuestra majestad, etc., puede ser negado, puede tomar adverbios, lo cual es prueba de la flexibilidad sintáctica de los enunciados objetivos.

Los ejemplos de (31b) muestran los contextos que debieron constituir el paso intermedio en el proceso de creación del marcador discursivo de desconocimiento y/o desinterés: el sujeto sintáctico está totalmente debilitado, ya que ha sido sustituido por una expresión impersonal con $s e$, el clítico impersonal indica que el posible sujeto del evento es semánticamente vago o desconocido; en el segundo ejemplo, al estar el sujeto, yo, en posición de tópico, se desvincula igualmente del verbo, y por lo tanto opera también en cierta forma el debilitamiento del control agentivo del sujeto, típico de los procesos de subjetivización.

El ejemplo de (31c) supone un paso más en el proceso de subjetivización: exhibe ya un sujeto inanimado que a primera vista parece no hacer sentido con el significado de saber, es, además, la única voz que puede concurrir en esta oración, es decir, no es sustituible por otro nominal inanimado ni es parafraseable el sintagma nominal; esto es, sólo se puede decir, con ese significado subjetivo, sepa la bola, residuo, sin duda, de un uso metonímico anterior, a partir de bola de gente, con el significado de 'multitud'; el verbo, a su vez, no puede tomar otros argumentos y debe construirse necesariamente en presente de subjuntivo, lo cual es muestra del debilitamiento semántico del verbo y de su rigidización sintáctica; la expresión toda constituye una frase hecha, totalmente lexicalizada en el español de México, y mediante ella el hablante indica su desconocimiento, con una carga de desinterés, en lo expresado por su interlocutor.

Finalmente, el ejemplo de (31d) muestra el último paso en el continuum evolutivo hacia la subjetivización y la cancelación de la capacidad verbal originaria; son enunciados fuertemente subjetivos: las formas verbales se han degradado categorialmente, aunque es reconocible todavía su carácter verbal, no hay flujo de transitividad, y aparecen las formas solas, son un enunciado en sí mismas, imposibilitadas de contraer relaciones con otras formas, incapaces de tomar argumentos e incapaces de ser repredicables o parafraseables. Estas formas 
aisladas operan no ya como verbos, sino como marcadores que codifican la actitud y valoración del hablante, concretamente su desconocimiento y desinterés respecto de lo comunicado por su interlocutor, la forma subjuntiva en que se (des)gramaticaliza el marcador discursivo contribuye a afianzar el significado de falta de certeza y desconocimiento de la expresión.

Al igual que ocurría en el cambio anterior, el marcador deverbal amplía su alcance, adquiere autonomía predicativa, sólo puede aparecer la forma sola o en una frase hecha, pierde, por tanto, integración gramatical, y pierde todo tipo de relacionalidad sintáctica; el debilitamiento del significado referencial etimológico de saber y la degradación del agente van también de la mano en esta serie de cambios.

El esquema 1 a continuación resume las características sintácticas de los dos procesos de subjetivización aquí analizados.

\title{
ESQUEMA 1
}

\section{Canal sintáctico de la subjetivización}

\begin{abstract}
Estado 1 no-subjetivo de la construcción = necesidad fuerte de sintaxis, distribución normal, alcance intraproposicional, integración sintáctica $\rightarrow$ Estado 2 subjetivo de la construcción = necesidad débil de sintaxis o pérdida de relacionalidad sintáctica, alcance extraproposicional, autonomía predicativa.
\end{abstract}

Pasemos ahora a valorar si este tipo de cambio es una gramaticalización o una desgramaticalización.

\section{EL CAMBIO VERBO > MARCADOR. ¿GRAMATICALIZACIÓN O DESGRAMATI- CALIZACIÓN?}

La diacronía de los verbos en su camino hacia marcadores discursivos muestra ciertos efectos propios de la gramaticalización, pero también otros que sugieren un camino de direccionalidad inversa. Veamos una por una las propiedades de la gramaticalización y comprobemos en qué medida el comportamiento de estos verbos son o no una gramaticalización. El esquema 2 abajo contrasta las propiedades de la gramaticalización, columna de la izquierda, con las propiedades de los cambios por subjetivización aquí tratados, columna de la derecha; el signo $\checkmark$ indica que es una propiedad compartida por ambos tipos 
de cambio, el signo $x$ debe leerse como que el cambio verbo $>$ marcador difiere de las características aceptadas para la gramaticalización ${ }^{62}$.

\author{
ESQUEMA 2 \\ Verbo $>$ marcador discursivo \\ ¿Gramaticalización o desgramaticalización?
}

\section{GRAMATICALIZACIÓN}

Debilitamiento del significado referencial Ganancia de significađo más abstracto (Erosión y pérdida de peso fonológico) (Univerbación)

Mecanismo básico: reanálisis

Extensión gradual a través de contextos Persistencia sintáctico-semántica etimol. Generalización

Ganancia de significado más gramatical Pérdida de libertad morfosintáctica Liberación de restricciones contextuales Incremento de frecuencia Obligatoriedad: necesidad del signo Reduccion de alcance $=$ intraproposic . Integración gramatical

Dirección: léxico/pragmática > sintaxis Menor variación diatópica

\section{SUBJETIVIZACIÓN: VERBO > MARCADOR}

El cambio verbo > marcador comparte con la gramaticalización, como vemos, buena parte de las características del proceso y del mecanismo y comparte las motivaciones, pero difiere sustancialmente de aquella en los resultados. Es, en efecto, un proceso similar pero con resultados opuestos. En vez de integrarse gramaticalmente y perder autonomía predicativa, el marcador deverbal pierde capacidades gramaticales y se vuelve una predicación autónoma, en vez de volverse obligatorios, se mantienen como elementos optativos -en efecto, no hay ninguna razón para que un hablante se obligue a emplear una expresión subjetiva-. La generalización requiere un comentario detenido: es muy posible que los marcadores se hayan también generalizado en cuanto que su empleo es muy frecuente, aunque no creo lleguen a la generalización de, por ejemplo, los auxiliares, sin embargo, es un resultado difícil de medir, porque la mayoría pertenece a lengua diaria coloquial, de difícil control cuantitativo.

62 Para una discusión similar a propósito de la ampliación de alcance de algunos adverbios en la historia del inglés, remito a Traugott, «The role of the development of discourse markers in a theory of grammaticalization», ponencia leída en el 12th International Conference on Historical linguistics, Universidad de Manchester, 1995. 
Otra diferencia -inexplorada hasta ahora, pero que bien pudiera ser objeto de estudio de otro trabajo- es, a mi modo de ver, el distinto grado de diferenciación dialectal que tienen las formas gramaticalizadas (en el sentido tradicional, definido al inicio de este trabajo) frente a las formas desgramaticalizadas; en efecto, parece logico pensar que las formas sometidas a procesos de gramaticalización tienen un grado menor de variación dialectal en cuanto que se integran a la gramática del español general y su uso se vuelve obligatorio, como son los casos, entre otros muchos, del auxiliar haber, los artículos determinado e indeterminado, los nexos subordinantes, que se emplean de manera bastante homogénea en el español general, desde luego con algunas diferencias dialectales, ya que la variación es inherente a la lengua. Por el contrario, las formas desgramaticalizadas que aquí estamos tratando muestran una diferenciación dialectal elevada, porque son dependientes del contextos pragmáticos y culturales específicos.

El cambio verbo > marcador difiere, por supuesto, en la direccionalidad, ya que sigue una direccionalidad inversa a la gramaticalización, puesto que «sale», se independiza, de la gramática para adquirir funciones pragmáticas. $\mathrm{Si}$ el peso de la prueba recae en la direccionalidad y en la cancelación de sintaxis, difícilmente se puede considerar una gramaticalización, en su sentido tradicional, el cambio verbo > marcador discursivo. Parece necesario concluir, entonces, que este tipo de cambio escapa a la definición tradicional de gramaticalización, y parece conveniente, entonces, caracterizarlos como una desgramaticalización o una pragmatización. Algunos autores han planteado ya el reto que la creación de marcadores discursivos, y en general los cambios por subjetivización, ofrece a la teoría de la gramaticalización ${ }^{63}$. En su opinión, estos cambios son gramaticalizaciones, un subtipo de gramaticalización, conscientes, sin embargo de que el aislamiento y empobrecimiento sintáctico, así como la ampliación de alcance y autonomía predicativa son propiedades problemáticas o huidizas para ser caracterizadas como una gramaticalización ortodoxa.

Sin embargo ni la etiqueta de desgramaticalización ni la, también comúnmente empleada, de pragmatización me parecen muy afortunadas: la primera no lo es por poner demasiado énfasis en la direccionalidad, un aspecto menor, a mi modo de ver, de los procesos de cambio sintáctico; la segunda no lo es porque parece sugerir que en la gramática no hay pragmática, y sí la hay; es decir, el término pragmatización plantea un problema teórico aún mayor, a saber, qué debe entenderse por gramática, qué entra y qué no.

63 Cf., entre otros, los ya citados Brinton, Pragmatic markers in English, Grammaticalization and discourse functions, cap. 9; Tabor y Traugott, «Structural scope expansion and grammaticalization»; Traugott, «The role of the development of discourse markers in a theory of grammaticalization», y Catherine Travis, «Dizque: A Colombian evidentiality strategy», trabajo leído en el 6th Hispanic Linguistics Symposiun, Ohio State University, 2002. 
A mi modo de ver, es conveniente mantener el concepto y el término de gramaticalización como un macrocambio dinámico, un cambio de cambios, que engloba distintas subclases y procesos. Un modo de solucionar el conflicto es adoptar una definición de gramaticalización más amplia, de tipo epistemológico, más que una etiqueta de tipo gramatical, es decir, reconceptualizar el término. Me refiero a la definición extrema, y sugerente, de gramaticalización formulada por Hopper en varios de sus trabajos, particularmente en 1987 y $1998^{64}$. Para el autor, la gramaticalización es la fuente fundamental de creación de gramáticas, y es un proceso altamente creativo similar a otras actividades creativas del ser humano, es un movimiento constante hacia la estructura, una búsqueda constante, nunca alcanzada de estructura, no existe la gramática sino sólo la gramaticalización. Las gramaticalizaciones se dan en la lengua en uso, en contextos discursivos reales, no hay estructura fija previa, de manera que la repetición y el carácter formulaico de buena parte del lenguaje, así como las frecuencias de uso de las formas, son factores determinantes en la codificación linguística; por tanto, una gramaticalización es la rutinización o cristalización del uso, sea cual sea la direccionalidad del cambio. Los signos se llenan contextualmente, no existe una lengua a priori, de ahí que la gramática sea heterogénea y contextualizada.

El cambio que aquí tratamos sería una gramaticalización, en la medida en que es también creación de gramática. Existe una gran permeabilidad bidireccional: pragmática > sintaxis, sintaxis > pragmática y con esta dinámica compleja se construye la gramática. No hay creación gramatical ex novo, sólo es un revolver y manipular la materia discursiva y gramatical preexistentes en ambas direcciones, esa es la esencia de la gramatica. Propongo distinguir entre Gramaticalización Oracional, o Gramaticalización 1, la gramaticalización que venimos denominando tradicional, y Gramaticalización Extraoracional, o Gramaticalización 2, los cambios que hasta aquí habíamos denominado desgramaticalización, diferenciación terminológica que sólo remitiría al diferente nivel de lengua en que una y otra suelen operar.

A favor de seguir considerando este tipo de cambio una gramaticalización está el hecho de que uno de los marcadores (verbo + clítico dativo) constituye una pauta estructural con una frecuencia de tipo muy alta, es decir es altamente productivo, no está fosilizado, no ha llegado a lexicalizarse —otros sí-, lo cual, sin duda, favorece una interpretación como gramaticalización.

${ }^{64}$ Cf. «Emergent grammar», Berkeley Linguistics Society, 13, 1987, págs. 139-157, «Energent gramman, en The new psychology of language. Cognitive and functional approaches to language structure, M. Tomasello (ed.), New Jersey, LEA, 1998, págs. 155-175. 


\section{CONCLUSIONES}

Hemos visto que los enunciados subjetivos producen un efecto de cancelación de la sintaxis normal de las formas involucradas, cancelación que debe ser entendida como prescindibilidad de sintaxis, esto es, prescindibilidad de los diversos aspectos descriptivos inherentes a esas formas; las formas que crean enunciados subjetivos suelen presentarse aisladas. Hemos establecido dos causas para esta cancelación sintáctica: la mayor profundidad histórica requerida para un cambio por subjetivización, y, sobre todo, el cambio de perspectiva del hablante, quien no está interesado en hablar de las formas, sino en hablar de cómo él ve las formas, en este proceso se prescinde de la sintaxis y las valoraciones, puntos de vista y actitudes del hablante encuentra codificación.

Hemos mostrado la flexibilidad categorial del verbo en la historia del español para recategorizarse como marcadores pragmáticos discursivos, y hemos analizado las propiedades semánticas y sintácticas comunes a todos esos verbos, que dan cuenta de un proceso diacrónico similar en todos ellos. Hemos hecho hincapié en la estrecha relación entre la elevada frecuencia de uso de esos verbos y la simultánea gramaticalización y desgramaticalización a que son sometidos. Hemos examinado en detalle un par de casos, poniendo atención en los contextos que produjeron la gradual desintactización de los verbos.

Finalmente hemos visto que la subjetivización comparte con la gramaticalización las motivaciones iniciales, y también buena parte de las características del proceso, pero difiere sustancialmente de aquella en los resultados, dado que en vez de integrarse en la gramática, las nuevas formas deverbales adquieren emancipación sintáctica y autonomía, características acordes con la desgramaticalización. Hemos propuesto asimismo la conveniencia de adoptar una definición amplia, más epistemológica, de gramaticalización, reconceptualizar el término de manera que sea posible considerar el tipo de cambios como los aquí analizados como una dinámica procesual, creativa y regular de generación de gramática. 